\title{
Habitat use of a coastal delphinid population investigated using passive acoustic monitoring
}

Palmer, K.J. ${ }^{1}$, Brookes, Kate L. ${ }^{2}$, Davies, I.M. ${ }^{2}$, Ewan Edwards ${ }^{2}$, Rendell, L. ${ }^{1}$.

${ }^{1}$ Sea Mammal Research Unit, School of Biology, University of St Andrews, Fife, KY16 9TH, UK

${ }^{2}$ Marine Scotland Science, 375 Victoria Road, Aberdeen, AB11 9DB, UK

\section{Abstract}

- The population of bottlenose dolphins in eastern Scotland has undergone significant range expansion since the 1990's, when a special area of conservation was established for the population.

- Distribution of this population is well described within areas of its range, where intensive work has been carried out, such as the inner Moray Firth, St Andrews Bay, and the Tay estuary area. However, elsewhere in their range, habitat use is less well understood.

- In this study, a large-scale and long-term passive acoustic array was used to gain a better understanding of bottlenose dolphin habitat use in eastern Scottish waters, complementing and augmenting existing visual surveys.

- Data from the array were analysed using a three-stage approach. First, acoustic occupancy results were reported; second, temporal trends were modelled; and third, a spatial-temporal-habitat model of acoustic occupancy was created.

- Results from the acoustic occupancy are in agreement with visual studies that found areas near known foraging locations were consistently occupied. Results from the trend 
analysis were inconclusive. Habitat modelling showed that, throughout their range, bottlenose dolphins are most likely to be detected closer to shore, and, for a constant distance to shore, in deeper water.

20 Keywords: Ocean, coastal, habitat management, Marine Protected Area, protected species,

21 mammals

\section{1. Introduction}

24 Bottlenose dolphins (Tursiops truncatus) are a cosmopolitan species with populations found in

25 tropical and temperate waters worldwide (Connor, Wells, Mann, and Read, 2000). Presently, the

26 International Union for Conservation of Nature lists the species as 'Least concern' indicating a

27 low risk of extinction. However, they are also listed under Appendix 2 of the Convention on the

28 Conservation of Migratory Species of Wild Animals indicating a need for, or benefit from,

29 international co-operation on conservation efforts. Off the eastern coast of Scotland, there is a

30 population of bottlenose dolphins consisting of approximately 200 individuals (Cheney et al.,

31 2013). The population is protected by a variety of national and international regulations,

32 including Annexes II and IV of European Union Habitats Directive (92/43/EEC), Wildlife and

33 Countryside Act (1981), and Joint Nature Conservation Committee UK Post-2010 Biodiversity

34 Framework. In 2005, as part of these conservation efforts, a Special Area of Conservation (SAC)

35 was established in the Moray Firth to protect habitat important to this population. The Moray

36 Firth SAC covers approximately $1500 \mathrm{~km}^{2}$ extending west from the Beauly Firth, north to

37 Helmsdale, and east to Lossiemouth (http//:www.jncc.defra.gov.uk; Figure 1). The management 
38 of the SAC has been implemented in such a way that the population is protected throughout its

39 range, whereby any activity which could have an adverse effect on the integrity of the site (i.e.

40 the protected features) is subject to a Habitats Regulations Appraisal (Arso Civil et al., 2019).

41 The range of this population extends well outside of the bounds of the SAC, with animals

42 commonly sighted along more than $200 \mathrm{~km}$ of coastal habitat (Paxton, Scott-Hayward,

43 Mackenzie, Rexstad, \& Thomas, 2016). Both within and outside the SAC, animals are known to

44 aggregate at certain locations, often associated with the mouths of rivers or estuaries (Hastie,

45 Wilson, \& Thompson, 2003, 2006; Hastie, et. al, 2004; Mendes, Turrell, Lütkebohle, \&

46 Thompson, 2002; Pirotta et al., 2014; Sargeant, Mann, Berggren, \& Krutzen, 2005; Wilson,

47 Thompson, \& Hammond, 1997). Because of the high encounter rates at these locations, some

48 have become focal areas for boat-based survey efforts, most notably the inner Moray Firth and

49 Firth of Tay. In some of these locations, henceforth termed points of aggregation, dolphins are

50 known to exploit tidal cycles and local bathymetry to maximise foraging efficiency (Hastie et al.,

51 2004). This is the case at two locations within the inner Moray Firth SAC: Chanonry Point near

52 the River Ness, and the entrance to the Cromarty Firth (Figure 1). At these locations deep

53 channels result in higher prey density at low tides and therefore may represent increased foraging

54 success for marine mammals (Thompson, Pierce, Hislop, Miller, \& Diack, 1991). Outside of the

55 Moray Firth SAC, points of aggregation have been observed around the mouth of the River Dee

56 (Sini, Canning, Stockin, \& Pierce, 2005), the Firth of Tay, and St Andrews Bay (Arso Civil et

57 al., 2019). While foraging activity has been observed at some of these locations, the underlying

58 factor(s) resulting in the higher occurrence are less clear for others. For example, dolphins are

59 commonly sighted in and around St Andrews Bay, which is a shallow water area with a small

60 estuary (Arso Civil et al., 2019; Quick \& Janik, 2012). 
61 Despite the large population range, most survey effort has focused on the Moray Firth and

62 specifically on well-established areas of high usage (Arso Civil, 2014; Arso Civil et al., 2019;

63 Bailey et al., 2010; Bailey \& Thompson, 2006; Hastie et al., 2006; Hastie et al., 2003; Janik \&

64 Thompson, 1996; Pirotta et al., 2014; Thompson, Brookes, \& Cordes, 2015; Wilson et al., 1997).

65 While these areas clearly represent key habitat for this population (Cheney et al., 2013), effective

66 conservation requires knowledge of habitat use throughout the population's range. Even in

67 foraging hotspots, bottlenose dolphin sightings are often not predictable (Culloch \& Robinson, 68 2008).

69 Since 2000, there have been a handful of regional scale surveys covering a large portion of the 70 population's habitat (Cheney et al., 2013). These include a compilation of visual and sightings

71 data from land and boat-based surveys (Thompson et al., 2011); a series of line transect surveys

72 between the Firth of Forth and the river Dee (Arso Civil, 2014), as well as some passive acoustic

73 studies (Cheney et al., 2013) . Together, results from these studies suggest that bottlenose

74 dolphins use the entirety of the coastal habitat, though less frequently outside of the Moray Firth

75 SAC than within it, and that animals are more likely to be sighted in waters within a few

76 kilometres of the shore. However, the relative lack of survey effort in other parts of the

77 population's range (Paxton et al., 2016) limits understanding of how these areas are used and

78 their relative importance to the population.

79 This lack of understanding has potential implications for the Habitats Regulations Appraisals

80 undertaken as part of the licensing of marine activities in the region, including the development

81 of offshore wind energy. Of particular concern is the lack of data in the regions most likely to

82 receive noise from wind farm construction activities, along with a lack of understanding of how

83 far offshore bottlenose dolphins range in these regions. Thompson, Brookes \& Cordes (2015) 
84 used a combination of fixed passive acoustic, and presence only visual survey data to model

85 usage of offshore areas by bottlenose dolphins. While they showed that it was unlikely that the

86 species used areas close to construction activities, the lack of data in the areas of concern

87 reduced stakeholder confidence in the findings.

88 To address these issues, the East Coast Marine Mammal Acoustic Study (ECoMMAS) (Marine

89 Scotaland Science, 2013) was started in 2013 to improve understanding of bottlenose dolphin use

90 of the east coast of Scotland, with effort spread more evenly throughout the region, including

91 data collection further offshore. The study uses fixed passive acoustic monitoring to complement

92 existing visual surveys in coastal and high-use areas. The data presented here were collected

93 during the first three years of the study.

94 C-PODs are commercially available echolocation click train detectors widely used for

95 monitoring cetaceans. The instruments are sold with a proprietary click train detector that

96 discriminates between 'noise' and the echolocation click trains (series of echolocation clicks)

97 produced by dolphins and porpoises. Over the last decade, studies using these devices have

98 contributed to our understanding of the behaviour and habitat use of the Moray Firth bottlenose

99 dolphin population (Graham et al., 2017; Pirotta, Merchant, Thompson, Barton, \& Lusseau,

100 2015; Pirotta et al., 2014).

101 Where multiple species are present however, discriminating between target (e.g. bottlenose

102 dolphin) and non-target species constitutes a major and ongoing challenge in the field of marine

103 passive acoustic monitoring. This is especially pertinent for studies using logging devices like C-

104 PODS that collect few acoustic features from which to classify the detections. To account for

105 this, users typically either deploy the instruments in habitats where only a single species is 
106 expected (Jaramillo-Legorreta et al., 2017) or assume the contribution of non-target species

107 detections to the analysis is limited (Pirotta et al., 2014; Thompson et al., 2011). Due to the scale

108 of the ECoMMAS array, neither assumption was applicable in this study. Throughout the survey

109 area, multiple species have been known to occur (Anderwald et al., 2010; Arso Civil, 2014;

110 Hammond et al., 2017). There is therefore a need to incorporate both acoustic classifiers and

111 classifier uncertainty into the analysis (Caillat, 2013).

112 In this research, a heuristic approach was taken to misclassification wherein species uncertainty

113 is built into the model response. An acoustic classification system (Palmer, Brookes, \& Rendell,

114 2017) was applied to C-POD detections in order to group detections into one of three classes:

115 broadband, frequency banded or unknown. The broadband category represents click trains

116 matching bottlenose dolphin and common dolphin (Delphinus spp. ) click characteristics and the

117 frequency banded category represents click trains matching white-beaked (Lagenorhynchus

118 albirostris) and Risso's (Grampus griseus) dolphin click characteristics (Calderan, Wittich,

119 Harries, Gordon, \& Leaper, 2013; Soldevilla et al., 2008). This analysis used the probability that

120 each echolocation click was broadband as the predictor for bottlenose dolphin presence, thereby

121 reducing the influence of non-target species on the model results.

122 Monitoring occupancy rates provides baseline data for future studies seeking to understand

123 changes in distribution over long timescales. In Scottish waters, long-term acoustic studies of

124 have been used to investigate the spatial and temporal distribution of harbour porpoises and

125 bottlenose dolphins, as well as model the potential impacts of anthropogenic activities (Brookes,

126 Bailey, \& Thompson, 2013; Harris et al., 2017; Simon et al., 2010; Williamson et al., 2016) . In

127 these studies, the presence of an acoustic signal characteristic of the animal (e.g. click or whistle)

128 is used as a proxy for true occupancy (P. Thompson et al., 2011). 
129 We expected to find low acoustic occupancy rates and the potential for misclassification was

130 high, so this research took a three-stage approach. In the first stage, two acoustic occupancy rates

131 are reported: proportion of acoustically monitored days containing acoustic encounters, and the

132 proportion of acoustically monitored days containing one or more broadband acoustic

133 encounters. The proportion of days with echolocation encounters is reported for the first three

134 years of the ECoMMAS survey.

135 The second stage of the study modelled temporal trends in acoustic occupancy from the first

136 three years of the ECoMMAS. As with baseline acoustic occupancy rates, identifying patterns in

137 annual occupancy trends should be of interest to regulators seeking to manage the effects of

138 offshore activities on dolphin habitat and behaviour.

139 The third stage of the analysis determined whether and to what extent it is possible to produce

140 spatial-temporal habitat models of broadband acoustic occupancy using ECoMMAS C-POD data

141 alone. In this portion of the analysis a model containing all available spatial and temporal

142 covariates was fitted to acoustic detections aggregated from the first three years of the

143 ECoMMAS study.

145 2. Methods

146 Data Collection

147 Data in this study were collected by 30 C-POD (version 1) echolocation click detectors

148 (Chelonia, Ltd, UK). Deployment locations were spread across the region of interest, in ten

149 groups of three; each group of three radiated out from the coast at approximately $5 \mathrm{~km}$ intervals 
150 to provide data at increasing distance offshore (figure 1). The 30 deployment locations are

151 identified by the combination of the group name (based on the nearest settlement on land) and

152 distance from shore (e.g. Cro_05 for the Cromarty nearshore location).

153 The entire array was deployed each spring and recovered in the fall. Precise deployment and

154 recovery times depended on ship availability and weather conditions (Table 1). With the

155 exception of the first deployment in 2015 , which was recovered prior to battery exhaustion, all

156 C-PODS ran continuously until either storage or battery capacity was exhausted.

158 Data Quality

\section{Acoustic Data Processing}

160 C-POD data from 2013-2015 were processed with the accompanying KERNO classifier version

1612.042 (www.chelonia.co.uk) for the presence of high or moderate quality "other cetacean" click

162 trains. The KERNO classifier annotates impulsive detections as narrow-band high frequency

163 (NBHF) click trains, 'Other cetacean' click trains and 'sonar'. NBHF detections are primarily

164 produced by porpoises. 'Other cetacean' click trains may be indicative of a variety of dolphin

165 species (Sarnocinska, Tougaard, Johnson, Madsen, \& Wahlberg, 2016). After processing for the

166 presence of 'other cetacean' clicks, click trains were grouped into acoustic encounters. Each

167 acoustic encounter consisted of all high or moderate quality 'other cetacean' click trains starting

168 within 20 minutes of the end of another click train. Acoustic encounters were subsequently

169 processed with the categorization system described in Palmer et al. (2017). This system

170 categorises each acoustic encounter into one of the following three categories; 'broadband',

171 'frequency banded', or 'unknown'. Thus, only acoustic encounters considered by the system to 
172 be at least five times more likely to be either broadband or frequency banded were categorised.

173 Encounters that failed to meet the classification threshold for either taxonomic group were

174 classified as unknown.

175 To incorporate classifier uncertainty into the analysis, the probability that broadband clicks were

176 detected $(\mathrm{P}($ Broadband $))$ was used as the response variable in the acoustic occupancy models

177 (Palmer et al 2017; supplementary material). Broadband click detection probability was defined

178 as the probability that broadband clicks were actually present, given the category produced by

179 the classification system. For days when no acoustic encounters were detected, P(Broadband)

180 was set to 0 . Days when only broadband acoustic encounters (as determined by the classification

181 system) were reported, $P$ (Broadband) was set to 0.79 , reflecting the known error rate as

182 determined by the classification confusion matrix. Similarly, for days when only frequency-

183 banded clicks were reported, $\mathrm{P}$ (Broadband) was 0.08 . For days when both broadband and

184 frequency banded click encounters were reported, complete uncertainty was assumed by setting

$185 P$ (Broadband) to 0.5 .

187 Temporal Covariates

188 The way temporal covariates were included in the models differed between the modelling stages.

189 For the second stage temporal models, time of the year was measured as the Julian day (1-365)

190 and included as a smooth continuous variable. For the third stage spatial-temporal model, there

191 were insufficient detections to incorporate time as a smoothed variable and thus, season was

192 included in the model as a three-level factor (Spring, Summer, or Autumn). Spring was defined

193 as the months between April and May (March data was not available), Summer (June to August) 
194 and Autumn (September to November). No data were collected over the winter season. For both

195 analyses, year was included as a three-level categorical predictor (2013, 2014 or 2015).

\section{Spatial Covariates}

197 As with temporal covariates, spatial covariates were included as either continuous or factor

198 variables. Previous studies have identified the following spatial covariates as potential predictors

199 for the presence of bottlenose dolphins: distance to nearest point of aggregation (e.g. Cromarty

200 Firth and River Dee), distance to shore, the gradient of the seabed (henceforth slope), and depth

201 (Thompson et al., 2015).

202 Distance to the nearest point of aggregation was included as a continuous variable in the spatial-

203 temporal model. Known points of aggregation have previously been shown to drive spatial and

204 temporal distribution of animals in this population and, in some areas, have been linked to

205 foraging (Hastie, Wilson, Wilson, Parsons, \& Thompson, 2004). Given the spatial and temporal

206 scale of this study, estuaries that may represent important habitat for animals either transiting

207 between the established points of aggregation or contemporaneous with local and/or ephemeral

208 prey sources were included. Known points of aggregation included the Cromarty Firth, Firth of

209 Tay, and the rivers Ness and Dee (Cheney et al., 2013; Hastie et al., 2004; Quick et al., 2014). To

210 the known points of aggregation, the mouths of the rivers Spey, North Esk, and Tweed were

211 added. River estuaries were selected from the Atlantic Salmon Rivers Database

212 (http://www.nasco.int/RiversDatabase.aspx). Distance to nearest point of aggregation was

213 reported as a continuous variable and was measured by calculating the distance between each C-

214 POD and the nearest point of aggregation. 
215 Distance to shore was measured as either a three-level factor corresponding to whether each C-

216 POD was deployed in nearshore (05), midshore (10), or offshore (15) habitat, or as a continuous

217 predictor. For the spatial-temporal model of acoustic occupancy, distance to shore was reported

218 as the continuous range between the deployment location and the distance to the nearest $0 \mathrm{~m}$

219 isobath (Pante \& Simon-Bouhet, 2013).

220 Deployment depth (in meters) was recorded from the ship at the time of deployment. Additional

221 spatial covariate data were obtained from the NOAA ETOPO1 database (Amante, 2009), with 1

222 arc-second resolution $(\sim 30 \mathrm{~m})$ and processed using the 'marmap' R package (Pante \& Simon-

223 Bouhet, 2013). Slope was calculated in radians using the Fleming and Hoffer algorithm through

224 the 'raster' R package (Fleming \& Hoffer, 1979; Hijmans \& van Etten, 2014). Depth and slope

225 were modelled as continuous predictors (see supplemental information for covariate details).

\section{Site-specific temporal trends}

227 Generalized estimating equations with splines (GEE-GAMs) were fitted to each of the ten

228 deployment groups based on a priori knowledge that bottlenose dolphin behaviour changes

229 throughout their range, depending on whether they are or are not near foraging areas (Hastie et

230 al., 2004; Pirotta et al., 2014; Thompson et al., 2013). GEE-GAMs were chosen for their flexible

231 modelling structures capable of handling binary data. Only data from C-PODs that returned at

232 least two days with 'other cetacean' detections were included in the temporal models. Temporal

233 autocorrelation in detections across consecutive days was accounted for by including in the

234 models an autoregressive correlation structure $(\operatorname{arl})$ to detections from each individual C-POD

235 deployment (Box, Jenkins, Reinsel, \& Ljung, 2015). 
236 For this analysis, model selection focused on estimating the form of the relationship between the 237 probability of detecting a broadband acoustic encounter and the Julian day of the year. For each

238 deployment, four models were investigated. Predictor variables for all models included

239 ShoreDist, a three level factor for distance from shore of the deployment location $(05,10,15)$, a

240 three level factor for survey year $(2013,2014$ or 2015) and an integer for Julian day of year.

241 The first model (Equation 1) assumed an interaction between the shore distance and Julian day of

242 year, and that the pattern in detections throughout the year could be modelled by a cubic B-

243 spline. The second model (Equation 2) assumed an interaction between the cubic B-spline and

244 the survey year. The third model (Equation 3) had no interactions between the cubic B-spline and

245 the shore distance or survey year, and the fourth model (Equation 4) assumed a parametric

246 linearrelationship between the daily probability of detecting a broadband echolocation click train,

$247 \mathrm{P}($ Broadband $)$, and the Julian day of year. In accordance with previous studies using cubic spline

248 models a single knot was set at the median of each C-POD record (Pirotta, Matthiopoulos,

249 MacKenzie, Scott-Hayward, \& Rendell, 2011). It was not possible to include more than one knot

250 in the spatial models, as the lost degrees of freedom prevented model convergence. All models

251 were fitted in R v.3.3.2 using the 'geepack' package (Halekoh, Højsgaard, \& Yan, 2006). B-

252 splines were added to the models using the 'splines' package (R Core Team, 2016).

$$
\begin{gathered}
\text { P(Broadband }) \sim \text { Year }+ \text { ShoreDist * } \\
b s(\text { JulianDay, } k n o t s=\text { median }(\text { JulianDay }))
\end{gathered}
$$




$$
\begin{array}{cr}
\text { P(Broadband }) \sim \text { ShoreDist }+ \text { Year * } & \\
\text { bs }(\text { JulianDay, knots }=\text { median(JulianDay })) & \text { Equation } 2 \\
P(\text { Broadband }) \sim \text { ShoreDist }+ \text { Year }+ & \text { Equation } 3 \\
\text { bs (JulianDay, knots }=\text { median(JulianDay })) & \\
P(\text { Broadband }) \sim \text { ShoreDist }+ \text { Year }+ \text { JulianDay } & \text { Equation } 4
\end{array}
$$

255 Akaike's Information Criterion (AIC) scores are commonly used to select between candidate

256 GAM or GLM models (Akaike, 1974). However, because GEE's are not likelihood-based

257 models, AIC scores cannot be calculated. Instead a quasi-likelihood criterion (QIC; Pan 2001)

258 was used to select between the four temporal acoustic occupancy models. Quasi-likelihood

259 criterion model selection mirrors AIC-based selection in application, but is appropriate for

260 selecting between GEE models.

261 Assessing how well the selected model fitted the data followed previous methods (Pirotta et al.,

262 2011; Thompson et al., 2013). For each deployment group, the model with the lowest QIC was

263 used to predict the probability of detecting a broadband echolocation click across the range of the

264 predictors. Receiver operating curves (ROCs; Fawcett, 2006) were then created to determine the

265 relationship between the detection threshold, and the false positive and false negative rates for

266 each model. ROC curves show the relationship between the proportions of true positive

267 detections, here the proportion of days with broadband echolocation click trains accurately

268 predicted, and the proportion of false positive detections or the proportion of days the model 
269 inaccurately predicted the presence of broadband echolocation click presence. True and false

270 positive rates are then plotted for each threshold. The threshold at which the trade-off between

271 true and false positive rates is approximately equal is referred to as the optimum threshold. Using

272 the ROC, an optimal detection threshold was selected above which broadband echolocation

273 clicks were assumed to be detected and below which they were not. Using optimum threshold,

274 confusion matrices were then created to measure the proportion of detection-positive and

275 detection-negative days correctly identified by the model. The area under the ROC curve (AUC)

276 was used to describe the model goodness-of-fit. AUC scores represent a measure of how well the

277 model predicts the data. AUC values of 0.5 indicate that the model correctly predicted $50 \%$ of

278 the observations and therefore, for a binomial model, values of 0.5 represent models that

279 performed as well as would be expected by chance alone. Considering the variation in the data, it

280 was relevant to determine how well each model fit all locations in the group. Thus, in addition to

281 assessing how well the selected model fit each deployment group, how well the winning model

282 fit the data from each C-POD deployment location was also investigated. Through this process

283 AUC scores were calculated for each model for each deployment group, as well as for all 30

284 individual deployment locations (Figure 1). These analyses were done in R using the 'ROCR'

285 v1.0-7 and 'PresenceAbsence' v1.19 packages (Freeman, 2007; Sing, Sander, Beerenwinkel, \&

286 Lengauer, 2005). The relationship between P(Broadband) and Julian day was then plotted for

287 each of the deployed C-PODs and years (Figures 3-5).

\section{Spatial-Temporal Habitat Modelling}

289 Bottlenose dolphins are known to move along the east coast of Scotland for foraging and other

290 purposes (Cheney et al., 2013; Thompson et al., 2013). The full model presented in this study 
291 included independent factors for slope, distance to point of aggregation, depth, and distance to

292 shore. Temporal covariates included only season as a factor (spring, summer, and autumn).

293 For this analysis, a generalized additive mixed model (GAMM; Wood 2006) that incorporated

294 both spatial and temporal variables was fitted to the data. Because smooth terms are centred

295 using the MGCV package, smooth terms were also added as a main effect, as per package

296 recommendations. As with the temporal models, an autoregressive correlation structure with

297 detections grouped by deployment site was included (Box et al., 2015). Only the 'ar1'

298 autocorrelation structure was investigated, based on biological understanding that acoustic

299 encounters spanning several days were unlikely to be driven by the same underlying factor.

300 The limited degrees of freedom in the data precluded fitting multiple models. Rather, a full

301 model was fitted that included at least one form of all spatial and temporal covariates. Model

302 covariates were investigated for collinearity using variance of inflation factors (VIF), and any

303 covariates with VIF scores greater than two were considered collinear (Craney \& Surles, 2002).

304 As the goal of this analysis was to produce a comprehensive model for habitat use, model

305 selection was limited to excluding variables with estimated degrees of freedom less than 1.

306 Adjusted r-squared and AUC scores were used to describe model fit.

307 The resulting model was used to predict the presence of broadband acoustic encounters in the

308 Scottish North Sea. A grid size of $1 \mathrm{~km}^{2}$, the approximate detection range of the C-PODs

309 (Nuuttila, Thomas, et al., 2013) was used. The prediction space was restricted to habitats that fell

310 within the parameters covered by the C-POD deployments including depth (103.0 - 9.3 m),

311 distance to nearest point of aggregation $(2.3-67.17 \mathrm{~km})$, and distance to shore $(0.35-17.9 \mathrm{~km})$. 


\section{3. Results}

\section{Acoustic Occupancy Rates}

315 Throughout the three years of survey reported in this study, 11,663 days of C-POD recordings

316 were collected. At only16 deployment sites, devices were retrieved in all three years (Figure 2

317 and Supplemental Material). C-PODs deployed at the Fraserburgh 10 site were not recovered in

3182013 and 2014 and did not detect any acoustic encounters in 2015. C-PODs at the Spey Bay 10

319 and Helmsdale 10 locations returned data for two of the three years but failed to document two

320 or more days with dolphin echolocation click trains. The C-PODs deployed at the St Andrews 10

321 location were successfully recovered in all three years but failed to detect dolphin echolocation

322 click trains on two or more days.

323 The C-POD deployed nearest to Cromarty Firth showed the highest acoustic occupancy rate,

324 with $78 \%$ of the days containing at least one broadband detection in 2013 , and $83 \%$ in 2015

325 (Table 2). There was wide variation in the acoustic occupancy rate and broadband occupancy

326 rate across the array. C-PODs deployed at the northern and southern ends of the survey area

327 (Latheron and St Abbs) had very low (<5\%) broadband occupancy rates for all survey years.

328 Broadband occupancy rates at the nearshore (05) deployment locations were typically greater

329 than the more offshore (10 or 15) locations. The mean broadband occupancy rates for the 05,10

330 and 15 locations were $0.12,0.03$ and 0.02 detections/day respectively. Excluding the Cromarty

33105 C-POD, the occupancy rate for the nearshore deployments was 0.06 detections/day, nearly

332 twice that of the mid or offshore locations (Table 2).

333 C-PODs in the Stonehaven deployment group were notable for having the second highest

334 acoustic occupancy rates behind the Cromarty group. Both broadband and frequency branded 
335 acoustic encounters were documented at these sites with similar frequency (Figure 2). The C-

336 PODs in this group detected echolocation click encounters on more than $15 \%$ of the survey days 337 and broadband encounters on at least $10 \%$ of the survey days.

\section{Site-Specific Temporal Trends}

340 Deployments at the Helmsdale 15, St Andrews 10, Fraserburgh 10, and Spey Bay 10 sites failed

341 to detect broadband clicks on at least two days and were removed from the temporal analysis.

342 Delta-QIC scores for temporal model selection were less than 3.5 for half of the deployment

343 groups indicating some uncertainty in model selection. Furthermore, AUC scores at some

344 individual deployment sites less than 0.5 (Table 3): equal to what would be expected by chance

345 alone. Even at sites with high AUC scores, the ability to predict days with broadband acoustic

346 encounters was 0.53 , indicating that nearly half the detections could not be explained by the

347 model. The lowest AUC score among the ten deployment groups was at the St Abbs group (AUC

$348=0.62$, Table 3 ), indicating it performed only slightly better than would be expected by chance

349 alone. The highest AUC was 0.93 determined for both the Helmsdale and Cromarty groups.

350 When model fit was investigated at each of the 30 deployment sites, AUC ranged from 0.2 at the

351 Cruden Bay 10 location to 0.99 at the Latheron 10 location (Table 2).

352 Low acoustic occupancy rates across most sites meant that the temporal models generally did 353 well at predicting periods without detections, but were poor at predicting detection-positive days.

354 Across the dataset, $43 \%$ of the days without broadband detections were accurately predicted,

355 with the exception of Cruden Bay, where $30 \%$ were correctly classified. Apart from the 
356 Cromarty group, no model was able to predict more than $20 \%$ of the broadband detection357 positive days.

358 Large ( $>3) \Delta$ QIC and high $(>0.75)$ AUC scores indicated a more confident model selection and

359 better model fit at the Latheron 10, St Andrews 15, Stonehaven 15, Spey Bay 10, and Helmsdale

36015 sites. Of these, only the Stonehaven 15 location contained broadband echolocation click

361 trains on greater than $1 \%$ of the days. Thus, high AUC scores at the other locations were

362 influenced by the correct prediction of days without dolphin detections.

363 For sites with the highest acoustic occupancy of broadband click trains, e.g. Cromarty 05 and

364 Stonehaven 15, GEE-GLM models suggested peaks in the probability of detecting broadband

365 echolocation encounters in August and July, respectively. At other locations, including

366 deployment sites in the Fraserburgh, Arbroath and St Andrews groups, temporal trends in

367 acoustic occupancy were highly stochastic. Poor model fits (AUC $<0.50)$ at the deployment sites

368 within these groups make it difficult to identify the presence and/or persistence of patterns in

369 daily acoustic occupancy (Figures 3-5).

\section{Spatial-Temporal Habitat Modelling}

371 VIF scores for spatial covariates were less than three and subsequently all spatial variables were

372 retained. In the full model the estimated degrees of freedom (EDF) for slope were less than one,

373 and the predictor was removed. In the final model, all terms were significant except season

374 (Table 4). The AUC score of the final model was 0.86. Modelling results suggested that the

375 probability of detecting broadband echolocation click train encounters decreased with increasing

376 distance to shore and increasing distance to the nearest point of aggregation. However, across the 
377 extent of the array, the probability of detecting broadband echolocation encounters increased

378 with increasing depth (Figure 6).

379 When the GAMM was projected over the available habitat, higher broadband occupancy was

380 predicted near the Inner Moray Firth and Dee river estuaries. The GAMM also predicted that C-

381 PODs deployed in nearshore areas were more likely to detect broadband encounters than those

382 deployed further offshore. Finally, deeper $(>60 \mathrm{~m})$ offshore areas were projected to have a higher

383 probability of broadband occupancy than shallow areas (Figure 7; see supplemental material for

384 projections of the confidence intervals as well as projections for Spring and Autumn).

386 4. Discussion

387 The primary goal of this study was to improve understanding of the patterns of habitat use by 388 this coastal bottlenose dolphin population throughout its range. A three-step approach was taken 389 to the analysis. First, daily acoustic occupancy rates were reported for all sites and for both 390 unfiltered acoustic encounters and echolocation click encounters identified as 'broadband' by the 391 classification system (Palmer et al., 2017). Second, models investigating temporal trends were 392 fitted to the available data to investigate seasonal occurrence patterns. Third, a spatial-temporal 393 model was fitted to the data to predict the animals' habitat use.

394 The study faced two main challenges: low acoustic occupancy rates and species classification 395 uncertainty. Low acoustic occupancy rates limited detection sample size. The autocorrelation 396 structure in the temporal model accounted for correlation within acoustic encounters, but further

397 limited the remaining degrees of freedom to model spatial and temporal trends in acoustic 398 occupancy. For half of the deployment groups, model selection techniques $(\Delta \mathrm{QIC})$ did not 
strongly favour one temporal model over another. This is indicative of variation not accounted

400 for by any of the models in the set. Larger amounts of acoustic data will be needed to produce

401 robust model estimates in future studies. For example, Pirotta et al. (2014) used data from eight

402 years of continuous surveys to produce estimates for dolphin foraging rates within the Moray

403 Firth SAC. In addition to having a longer sample period, echolocation detectors in Pirotta et al.

404 (2014) were deployed in areas of high use and therefore registered a higher rate of detections.

405 Future deployments of the ECoMMAS will address some of the temporal modelling issues this

406 work encountered, as gaps in data coverage are reduced through multiple annual deployments, as

407 was done in 2015.

408 Despite their lack of species resolution, C-PODs remain widely used instruments for passive 409 acoustic monitoring (Cox et al., 2017; Jaramillo-Legorreta et al., 2017; Nuuttila, Meier, et al., 410 2013; Williamson et al., 2016; Wilson, Benjamins, \& Elliott, 2013). Nearly all studies that use

411 the instruments simply assume that the target species, here bottlenose dolphins, are responsible

412 for the preponderance of the detections. This study improves to some degree on that assumption

413 by applying a secondary classification system to the detections. This system is unable to

414 discriminate between some species of dolphins and enhanced taxonomic resolution is unlikely to

415 be achievable with these devices. Even with full spectrum recordings, it is exceptionally difficult

416 to discriminate between echolocation clicks of common and bottlenose dolphins (Soldevilla et

417 al., 2008).

418 Species discrimination was improved over the Chelonia classifier, but perfect dolphin

419 classification is impossible for any passive acoustic study, regardless of the recording device or 420 sample frequency (Caillat, 2013; Roch et al., 2011). As such, these findings emphasise the need 421 to combine long term data from visual and acoustic surveys. In doing so, researchers will be able 
422 to provide robust data on long-term trends in dolphin occurrence throughout the habitat and for

423 areas of ecological or commercial interest (Thompson et al., 2011).

424 This is the first acoustic study that approximates the entire geographic range of this population.

425 The ECoMMAS, in combination with Arso Civil et al. (2019), provides critical information

426 about baseline habitat use. Such information is needed to monitor change in habitat use through

427 time (Bailey et al., 2010). A novel classification algorithm on the 'other cetacean' detections

428 reported by the C-POD software was used. The additional information produced by the

429 classification algorithm enabled both the temporal and spatial-temporal model to more closely

430 focus on the species of interest. Thus, this research required fewer assumptions about the impact

431 of non-target species detections on the resulting models.

432 Patterns in broadband acoustic occupancy rates were generally consistent with previous research

433 suggesting the bottlenose dolphins are more likely to be observed in coastal waters, within $5 \mathrm{~km}$

434 of shore (Arso Civil, 2014). While most instruments were deployed in less than $30 \mathrm{~m}$ of water,

435 broadband acoustic occupancy rates throughout the survey were generally higher for C-PODs

436 closer to the shoreline (Table 3; Figure 2). This supports the work of Thompson, Brookes \&

437 Cordes (2015) and increases the confidence that bottlenose dolphins are unlikely to be present in

438 areas that may be exposed to significant construction noise from offshore wind farms.

439 Acoustic occupancy rates and habitat modelling highlight the waters between Stonehaven and

440 Aberdeen as a potential area of high occupancy. Instruments deployed in the Stonehaven group

441 showed the second highest acoustic occupancy rates behind the Cromarty group. In 2013 and

442 2015, the Stonehaven 15 and 05 (respectively) C-PODs documented dolphin presence on at least

$44330 \%$ of the monitored days (Table 3). Moreover, both broadband and frequency banded click 
444 trains were documented at these sites at nearly equal rates, suggesting a potential hotspot

445 important for multiple species. Previous studies have shown that dolphins are present in coastal

446 waters north and south of Stonehaven year-round (Thompson et al., 2011). Historically, white-

447 beaked and bottlenose dolphin sightings have been common in visual surveys (Anderwald et al.,

448 2010; Arso Civil, 2014; Weir, Stockin, \& Pierce, 2007). Thus, further research to determine

449 whether the area constitutes a biological hotspot is warranted.

450 Modelling efforts for temporal trends across the spatial and temporal extent of the array were

451 challenged by few detections and gaps in data coverage. As such, the inference that can be made

452 from the models is highly limited. Despite these challenges, the model for the Cromarty group

453 did fit well and indicated a peak in broadband detections consistent with earlier visual surveys

454 (Thompson et al., 2011). The novel approach to classification uncertainty reduced the number of

455 days with echolocation encounters in the dataset. While this conservative approach hindered

456 modelling efforts in this research, it will provide more robust estimates of dolphin species

457 distributions as the survey matures (Pirotta et al., 2014).

458 Spatial-temporal habitat selection modelling was more successful and generally agreed with

459 previous studies linking smaller distances to shore with increased probability of detecting

460 bottlenose dolphins (Arso Civil, 2014; Pirotta et al., 2014; Quick et al., 2014). The spatial

461 modelling suggested that broadband acoustic encounters were more likely to be detected in

462 deeper water and predicted a slight increase in detections $>15 \mathrm{~km}$ from shore (Figures 5-6).

463 Without concurrent visual confirmation residual uncertainty remains regarding whether and to

464 what extent echolocation encounters detected at offshore locations represented common

465 dolphins. The spatial-temporal model indicated that distance to the nearest selected point of

466 aggregation and depth were also important predictors of broadband occupancy. Unfortunately, 
467 there were not enough detection data to model the spatial and temporal covariates together (e.g.

468 Julian day of year and depth).

469 Bottlenose dolphins are commonly sighted in St Andrews Bay (Arso Civil et al., 2019; Quick et

470 al., 2014), so the low number of detections at the St Andrews survey location nearest the bay (St

471 Andrews 05) was somewhat unexpected. There are several possible reasons for this. One

472 possibility is that the area may represent habitat associated with rest or socializing rather than

473 foraging, so there are fewer clicks to detect. Previous studies have found lower detection rates

474 for groups of animals, travelling and socializing animals, than single animals or foraging animals

475 (Nuuttila, Thomas, et al., 2013). If animals near the Fife Ness survey sites were primarily

476 travelling or socializing, they may not have been detected at rates comparable to foraging

477 animals. These results reinforce the need to integrate visual and acoustic surveys when managing

478 highly mobile species.

479 Unfortunately, the limited taxonomic resolution of the acoustic data means that it is not possible 480 to say with a high degree of certainty which of the broadband or frequency banded species were 481 present at these locations. Delphinid species classification is an issue that other studies using C482 PODs have not typically had the tools to address. This study uses improved classification 483 measures to more reliably discriminate between the various species present in the area.

484 Furthermore, the maximum acoustic occupancy probability of 0.79 for broadband acoustic 485 encounters is not a direct representation of true bottlenose dolphin occupancy. Thus, 486 conservative interpretation of these results, including relative occupancy between the survey 487 locations, is prudent. 
In situations where species classification remains an outstanding problem it is appropriate to

489 combine inferences from multiple survey methodologies (Cheney et al., 2013; Thompson et al.,

490 2015). In this survey region, visual surveys provide evidence that the majority of the broadband

491 echolocation encounters detected at the near-shore deployments originated from bottlenose

492 dolphins (Anderwald et al., 2010; Arso Civil, 2014; Arso Civil et al., 2019; Thompson et al.,

493 2013). Considerable uncertainty remains regarding broadband detections from offshore areas that

494 lack consistent visual survey effort. Where there are increased broadband detections at the

495 offshore locations, the data warrant further investigation, but classification is not possible. These

496 areas would benefit from either increased visual survey effort or more advanced acoustic

497 techniques that have recently shown promise in discriminating between common and bottlenose

498 dolphins (Frasier et al., 2017).

499 Data presented here also represent a small spatial sample, and acoustic data are lacking from

500 many important sites such as the River Dee and Tay estuary. In these, shipping activity has

501 restricted the use of acoustic moorings which may present a potential navigational hazard. Thus,

502 it has not been possible to deploy acoustic recorders in some known points of aggregation.

503 Appropriate sampling methods for investigating temporal and spatial trends are diametrically

504 opposed. If the continued goal of the ECoMMAS array is to relate habitat data to acoustic

505 occupancy, managers should consider changing deployment locations at each recovery and re-

506 deployment. However, if the goal is to maintain a historical record of the trends in acoustic

507 occupancy at these locations it is important that the deployment locations remain consistent.

508 From a conservation and management perspective, knowledge of where animals are is equally as

509 valuable as knowledge of where they are not. The ECoMMAS provides continuous survey

510 coverage for areas where consistent visual surveys are untenable. The first ecological results of 
511 ECoMMAS are consistent with visual sightings highlighting the importance of particular high-

512 usage areas to the population (Arso Civil et al., 2019). Similarly, daily acoustic occupancy rates

513 in areas between established points of aggregation were an order of magnitude lower. In sites

514 other than Cromarty 05, there was no clear trend in temporal detections. Thus, by themselves,

515 these results do not suggest the need to change any of the existing regulatory framework for this

516 population of bottlenose dolphins.

517 Bottlenose dolphins are highly mobile and adaptable generalists, capable of exploiting changing

518 environments (Santos et al., 2001). The areas currently considered to be critical habitat for this

519 population (e.g. the SAC) may shift with changing climate or other anthropogenic impacts. For

520 example, the point of aggregation near the Cromarty Firth has conclusively been linked with

521 foraging (Hastie et al. 2003). If the area no longer provides optimal foraging habitat, dolphins

522 will likely move elsewhere. Under such dynamic systems fixed protected areas may not provide

523 optimal conservation solutions for either protected species or human users. Dynamic ocean

524 management plans represent a flexible conservation approach that mirror the spatial and

525 temporal variability present in marine systems (Maxwell et al., 2015). Such management plans

526 have been implemented in North America where vessel speed restrictions may be triggered when

527 critically endangered North Atlantic right whales (Eubalaena glacialis) are visually or

528 acoustically detected near shipping lanes (Spaulding et al., 2009; Van Parijs et al., 2009). These

529 dynamic management areas are designed to provide maximum protection from anthropogenic

530 mortality while limiting additional regulatory burden on users. In a changing regulatory

531 landscape, there may be opportunities to rethink the implementation of conservation measures

532 for highly mobile species. Since the establishment of the Moray Firth SAC, the population has

533 grown and is now observed using the entire coastline (Cheney et al., 2013; Arso Civil et al. 
534 2019). This range expansion over a relatively short period might be reflected in a dynamic 535 management plan that considers variation in animal presence and the timing of ecological

536 features (e.g. diadromous fish runs or seasonal patterns in habitat use). Under dynamic

537 management plans, surveys like the ECoMMAS would be invaluable in providing detailed 538 information about habitat over longer periods than can be provided by visual surveys alone.

\section{Acknowledgments}

540 We are especially grateful to the deployment and recovery crews from Marine Scotland Science,

541 Moray First Marine, and the crew of the Northern Lighthouse Board vessel, Polestar. Sophie

542 Smout and Dave Miller provided useful feedback on statistical analysis for which we are much

543 indebted. LR and KJP were supported by Marine Scotland Science and the Marine Alliance for

544 Science and Technology for Scotland (MASTS) pooling initiative, and their support is gratefully

545 acknowledged. MASTS is funded by the Scottish Funding Council (grant reference HR09011)

546 and contributing institutions. We are also grateful to Paul Thompson, John Baxter, and two

547 anonymous reviewers for providing helpful comments on the manuscript. 


\section{Literature Cited}

Akaike, H. (1974). A new look at the statistical model identification. IEEE transactions on automatic control, 19(6), 716-723.

Amante, C. (2009). ETOPO1 1 arc-minute global relief model: procedures, data sources and analysis: US Department of Commerce, National Oceanic and Atmospheric Administration, National Environmental Satellite, Data, and Information Service, National Geophysical Data Center, Marine Geology and Geophysics Division Colorado. http://www. ngdc.noaa.gov/mgg/global/global.html. doi:10.7289/V5C8276M

Anderwald, P., Evans, P. G., Canning, S., Hepworth, K., Innes, M., Mcdonald, P., Sim, I., Stokin, K., Weir, C. (2010). Cetaceans of the East Grampian Region. Sea Watch Foundation, Aberdeen,

UK. Retrieved from https://www.seawatchfoundation.org.uk/wp-content/uploads/2012/08/Eastgramp-cet-rev.pdf. Last Accessed: 30/04/2019.

Arso Civil, M. (2014). PhD Thesis: Population ecology of bottlenose dolphins (Tursiops truncaturs) of the East Coast of Scotland. http://hdl.handle.net/10023/6543.

Arso Civil, M., Quick, N., Cheney, B., Pirotta, E., Thompson, P., \& Hammond, P. (2019). Changing distribution of the east coast of Scotland bottlenose dolphin population and the challenges of areabased management. Aquatic Conservation: Marine and Freshwater Ecosystems, This Volume.

Bailey, H., Clay, G., Coates, E. A., Lusseau, D., Senior, B., \& Thompson, P. M. (2010). Using T-PODs to assess variations in the occurrence of coastal bottlenose dolphins and harbour porpoises. Aquatic Conservation: Marine and Freshwater Ecosystems, 20(2), 150-158.

Bailey, H., \& Thompson, P. (2006). Quantitative analysis of bottlenose dolphin movement patterns and their relationship with foraging. Journal of Animal Ecology, 75(2), 456-465.

Box, G. E., Jenkins, G. M., Reinsel, G. C., \& Ljung, G. M. (2015). Time series analysis: forecasting and control: John Wiley \& Sons.

Brookes, K. L., Bailey, H., \& Thompson, P. M. (2013). Predictions from harbor porpoise habitat association models are confirmed by long-term passive acoustic monitoring. The Journal of the Acoustical Society of America, 134(3), 2523-2533. 
Caillat, M. (2013). Assessing and correcting for the effects of species misclassification during passive acoustic surveys of cetaceans. (PhD), University of St Andrews,

Calderan, S., Wittich, A., Harries, O., Gordon, J., \& Leaper, R. (2013). White-beaked dolphin and Risso's dolphin click characteristics and the potential for classification and species identification. Scottish Natural Heritage Commissioned Report No. 624 Retrieved from http://www.snh.org.uk/pdfs/publications/commissioned_reports/624.pdf. Last Accessed: 21/05/2018. 
Graham, I. M., Pirotta, E., Merchant, N. D., Farcas, A., Barton, T. R., Cheney, B., .. . Thompson, P. M. (2017). Responses of bottlenose dolphins and harbor porpoises to impact and vibration piling noise during harbor construction. Ecosphere, 8(5), e01793.

Halekoh, U., Højsgaard, S., \& Yan, J. (2006). The R package geepack for generalized estimating equations. Journal of Statistical Software, 15(2), 1-11.

Hammond, P., Lacey, C., Gilles, A., Viquerat, S., Boerjesson, P., Herr, H., Macleod. K., Ridoux, V., Santos, M.b., Scheidat, M., Teilmann, J., Vingada, J., Øien, N. (2017). Estimates of cetacean abundance in European Atlantic waters in summer 2016 from the SCANS-III aerial and shipboard surveys. Retrieved from: https://synergy.standrews.ac.uk/scans3/files/2017/04/SCANS-III-design-based-estimates-2017-04-28final.pdf. Last Accessed: 21/05/2018.

Harris, C. M., Thomas, L., Falcone, E. A., Hildebrand, J., Houser, D., Kvadsheim, P. H., Lam, F.P.A., Miller, P.J., Moretti, Read, A. J. (2017). Marine mammals and sonar: doseresponse studies, the risk-disturbance hypothesis and the role of exposure context. Journal of Applied Ecology, 55(1), 369-404.

Hastie, G., Wilson, B., \& Thompson, P. (2003). Fine-scale habitat selection by coastal bottlenose dolphins: application of a new land-based video-montage technique. Canadian Journal of Zoology-Revue Canadienne De Zoologie, 81(3), 469-478.

Hastie, G., Wilson, B., \& Thompson, P. (2006). Diving deep in a foraging hotspot: acoustic insights into bottlenose dolphin dive depths and feeding behaviour. Marine Biology, 148(5), 1181-1188.

Hastie, G. D., Barton, T. R., Grellier, K., Hammond, P. S., Swift, R. J., Thompson, P. M., \& Wilson, B. (2003). Distribution of small cetaceans within a candidate Special Area of Conservation; implications for management. Journal of Cetacean Research and Management, 5(3), 261-266.

Hastie, G. D., Wilson, B., Wilson, L., Parsons, K., \& Thompson, P. (2004). Functional mechanisms underlying cetacean distribution patterns: hotspots for bottlenose dolphins are linked to foraging. Marine Biology, 144(2), 397-403.

Hijmans, R. J., \& van Etten, J. (2014). raster: Geographic data analysis and modeling. $R$ package version, 2,15 . 
Janik, V. M., \& Thompson, P. M. (1996). Changes in surfacing patterns of bottlenose dolphins in response to boat traffic. Marine Mammal Science, 12(4), 597-602.

Jaramillo-Legorreta, A., Cardenas-Hinojosa, G., Nieto-Garcia, E., Rojas-Bracho, L., Ver Hoef, J., Moore, J., Tregenza, N., Barlow, J., Gerrodette, T., Thomas, L., Taylor, B. (2017). Passive acoustic monitoring of the decline of Mexico's critically endangered vaquita. Conservation Biology, 31(1), 183-191. Retrieved from https://www.ncbi.nlm.nih.gov/pubmed/27338145. doi:10.1111/cobi.12789

Maxwell, S. M., Hazen, E. L., Lewison, R. L., Dunn, D. C., Bailey, H., Bograd, Briscoe, S. J., Fossette , D.K., Hobday, S., Bennett, A.J., Benson, M. (2015). Dynamic ocean management: Defining and conceptualizing real-time management of the ocean. Marine Policy, 58, 42-50.

Mendes, S., Turrell, W., Lütkebohle, T., \& Thompson, P. (2002). Influence of the tidal cycle and a tidal intrusion front on the spatio-temporal distribution of coastal bottlenose dolphins. Marine Ecology Progress Series, 239, 221-229.

Nuuttila, H. K., Meier, R., Evans, P. G. H., Turner, J. R., Bennell, J. D., \& Hiddink, J. G. (2013). Identifying Foraging Behaviour of Wild Bottlenose Dolphins (Tursiops truncatus) and Harbour Porpoises (Phocoena phocoena) with Static Acoustic Dataloggers. Aquatic Mammals, 39(2), 147-161.

Nuuttila, H. K., Thomas, L., Hiddink, J. G., Meier, R., Turner, J. R., Bennell, J. D., Bennell, J.D., Tregenza, N.C., Evans, P. G. (2013). Acoustic detection probability of bottlenose dolphins, Tursiops truncatus, with static acoustic dataloggers in Cardigan Bay, Wales. The Journal of the Acoustical Society of America, 134(3), 2596-2609.

Palmer, K. J., Brookes, K., \& Rendell, L. (2017). Categorizing click trains to increase taxonomic precision in echolocation click loggers. The Journal of the Acoustical Society of America, $142(2), 863$.

Pante, E., \& Simon-Bouhet, B. (2013). marmap: a package for importing, plotting and analyzing bathymetric and topographic data in R. PloS one, 8(9), e73051.

Paxton, C. G. M., Scott-Hayward, L. A. S., Mackenzie, M., Rexstad, E., \& Thomas, L. (2016). Revised Phase III Data Analysis of Joint Cetacean Protocol Data Resources with Advisory Note, JNCC Report 517, ISSN 0963-8091. Retrieved from http://jncc.defra.gov.uk/page-7201. Last Accessed: 30/04/2018. 
671 Perrin, W. F., Würsig, B., \& Thewissen, J. (2009). Encyclopedia of marine mammals (Second ed.): Academic Press.

673 Pirotta, E., Matthiopoulos, J., MacKenzie, M., Scott-Hayward, L., \& Rendell, L. (2011). Modelling sperm whale habitat preference: a novel approach combining transect and follow data. Marine Ecology Progress Series, 436, 257-272.

Pirotta, E., Merchant, N. D., Thompson, P. M., Barton, T. R., \& Lusseau, D. (2015). Quantifying the effect of boat disturbance on bottlenose dolphin foraging activity. Biological Conservation, 181, 82-89.

Pirotta, E., Thompson, P. M., Miller, P. I., Brookes, K. L., Cheney, B., Barton, T. R., Graham, I., Lusseau, D. (2014). Scale-dependent foraging ecology of a marine top predator modelled using passive acoustic data. Functional Ecology, 28(1), 206-217.

Quick, N. J., Arso, M., Cheney, B., Valentina, I., Janik, V., Thompson, P., \& Hammond, P. S. (2014). The east coast of Scotland bottlenose dolphin population: Improving understanding of ecology outside the Moray Firth SAC. Retrieved from https://www.gov.uk/government/uploads/system/uploads/attachment_data/file/346326/O ESEA2_east_coast_of_Scotland_bottlenose_dolphin_population.pdf. Last Accessed: 30/04/2018.

Quick, N. J., \& Janik, V. M. (2012). Bottlenose dolphins exchange signature whistles when meeting at sea. Proceedings of the Royal Society B-Biological Sciences, 279(1738), 25392545

R Core Team. (2016). R Foundation for Statistical Computing, Vienna, Austria (Version 3.2.4). Vienna, Austria: R Foundation for Statistical Computing. Retrieved from https://www.Rproject.org/

Roch, M. A., Klinck, H., Baumann-Pickering, S., Mellinger, D. K., Qui, S., Soldevilla, M. S., \& Hildebrand, J. A. (2011). Classification of echolocation clicks from odontocetes in the Southern California Bight. The Journal of the Acoustical Society of America, 129(1), 467-475.

Santos, M., Pierce, G. J., Reid, R., Patterson, I., Ross, H., \& Mente, E. (2001). Stomach contents of bottlenose dolphins (Tursiops truncatus) in Scottish waters. Journal of the Marine Biological Association of the United Kingdom, 81(5), 873-878. 
Sargeant, B. L., Mann, J., Berggren, P., \& Krutzen, M. (2005). Specialization and development of beach hunting, a rare foraging behavior, by wild bottlenose dolphins (Tursiops sp.). Canadian Journal of Zoology-Revue Canadienne De Zoologie, 83(11), 1400-1410.

Sarnocinska, J., Tougaard, J., Johnson, M., Madsen, P. T., \& Wahlberg, M. (2016). Comparing the performance of C-PODs and SoundTrap/PAMGUARD in detecting the acoustic activity of harbor porpoises (Phocoena phocoena). Paper presented at the Proceedings of Meetings on Acoustics, Fourth International Conference on the Effects of Noise on Aquatic Life. Dublin, Ireland. July 10-16

Science, M. S. (2013). The East Coast Marine Mammal Acoustic Study (ECOMMAS). Topic Sheet NO 126 V1. . Retrieved From: http://www.gov.scot/Resource/0042/00426891.pdf Last Accessed: 30/04/2018.

Simon, M., Nuuttila, H., Reyes-Zamudio, M. M., Ugarte, F., Verfub, U., \& Evans, P. G. H. (2010). Passive acoustic monitoring of bottlenose dolphin and harbour porpoise, in Cardigan Bay, Wales, with implications for habitat use and partitioning. Journal of the Marine Biological Association of the United Kingdom, 90(8), 1539-1545.

Sing, T., Sander, O., Beerenwinkel, N., \& Lengauer, T. (2005). ROCR: visualizing classifier performance in R. Bioinformatics, 21(20), 3940-3941.

Soldevilla, M. S., Henderson, E. E., Campbell, G. S., Wiggins, S. M., Hildebrand, J. A., \& Roch, M. A. (2008). Classification of Risso's and Pacific white-sided dolphins using spectral properties of echolocation clicks. The Journal of the Acoustical Society of America, 124(1), 609-624.

Spaulding, E., Robbins, M., Calupca, T., Clark, C. W., Tremblay, C., Waack, A., Ward, A., Kemp, J., Newhall, K. (2009). An autonomous, near-real-time buoy system for automatic detection of North Atlantic right whale calls. Paper presented at the Proceedings of Meetings on Acoustics (6). doi: 10.1121/1.3340128

Thompson, P., Brookes, K. L., Cordes, L. S., Barton, T., Cheney, B., \& Graham, I. M. (2013). Assessing the Potential Impact of Oil and Gas Exploration Operations on Cetaceans in the Moray Firth. Third year Report for DECC, Scottish Government, COWRIE, and Oil \& Gas UK. Retrieved from https://www.gov.uk/government/uploads/system/uploads/attachment_data/file/50021/mfresults2.pdf. Last Accessed: 30/04/2018. 
Thompson, P. M., Cheney, B., Ingram, S., Stevick, P. T., Wilson, B., \& Hammond, P. S. (2011).

Distribution, abundance and population structure of bottlenose dolphins in Scottish waters. Scottish Government and Scottish Natural Heritage funded report. Scottish Natural Heritage Commissioned Report No. 354. Retrieved from https://www.abdn.ac.uk/lighthouse/documents/SNH Report 354 Distribution abundanc e .pdf. Last Accessed: 30/04/2018.

Thompson, P., Pierce, G., Hislop, J., Miller, D., \& Diack, J. (1991). Winter foraging by common seals (Phoca vitulina) in relation to food availability in the inner Moray Firth, NE Scotland. The Journal of Animal Ecology, 283-294.

Thompson, P. M., Brookes, K. L., \& Cordes, L. S. (2015). Integrating passive acoustic and visual data to model spatial patterns of occurrence in coastal dolphins. ICES Journal of Marine Science, 72(2), 651-660.

Van Parijs, S. M., Clark, C. W., Sousa-Lima, R. S., Parks, S. E., Rankin, S., Risch, D., \& van Opzeeland, I. (2009). Management and research applications of real-time and archival passive acoustic sensors over varying temporal and spatial scales. Marine Ecology Progress Series, 395, 21-36.

Weir, C. R., Stockin, K. A., \& Pierce, G. J. (2007). Spatial and temporal trends in the distribution of harbour porpoises, white-beaked dolphins and minke whales off Aberdeenshire (UK), north-western North Sea. Journal of the Marine Biological Association of the United Kingdom, 87(1), 327-338.

Williamson, L. D., Brookes, K. L., Scott, B. E., Graham, I. M., Bradbury, G., Hammond, P. S., \& Thompson, P. M. (2016). Echolocation detections and digital video surveys provide reliable estimates of the relative density of harbour porpoises. Methods in Ecology and Evolution, 7(7), 762-769.

Wilson, B., Benjamins, S., \& Elliott, J. (2013). Using drifting passive echolocation loggers to study harbour porpoises in tidal-stream habitats. Endangered Species Research, 22(2), $125-U 152$.

Wilson, B., Thompson, P. M., \& Hammond, P. S. (1997). Habitat use by bottlenose dolphins: seasonal distribution and stratified movement patterns in the Moray Firth, Scotland. Journal of Applied Ecology, 34(6), 1365-1374. 
763 Wood, S.N. (2006) Generalized Additive Models: An Introduction with R. Boca Raton, FL:

764 Chapman \& Hall/CRC. 
766 Table 1. Deployment and recovery months of the ECoMMAS array in the three years of data

767 collection used in this study. In 2015 two consecutive deployments were undertaken.

\begin{tabular}{|l|l|l|}
\hline Year & Deployment & Recovery \\
\hline 2013 & June and July & October \\
\hline 2014 & May & November \\
\hline 2015 & $\begin{array}{l}\text { April } \\
\text { July }\end{array}$ & $\begin{array}{l}\text { July } \\
\text { November }\end{array}$ \\
\hline
\end{tabular}

768

769

770

771

772

773 
Table 2. Daily acoustic occupancy rates (number of days with detections/days with acoustic coverage) for unprocessed C-POD data

775 (All) and detections classified as "broadband" by the classification system. Ninety-five percent binomial confidence intervals in

776 parenthesis. Black areas indicated C-PODs that were not recovered or failed to record data.

\begin{tabular}{|c|c|c|c|c|c|c|}
\hline & Occ. Rate (All) & $\begin{array}{l}\text { Occ. Rate } \\
\text { (Broadband) }\end{array}$ & Occ. Rate (All) & $\begin{array}{l}\text { Occ. Rate } \\
\text { (Broadband) }\end{array}$ & Occ. Rate (All) & $\begin{array}{l}\text { Occ. Rate } \\
\text { (Broadband) }\end{array}$ \\
\hline Lat_05 & $0.19(0.12-0.28)$ & $0.00(0.00-0.04)$ & $0.00(0.00-0.04)$ & $0.00(0.00-0.04)$ & $0.20(0.15-0.26)$ & $0.00(0.00-0.03)$ \\
\hline Lat_10 & $0.03(0.01-0.08)$ & $0.01(0.00-0.05)$ & & & $0.04(0.02-0.08)$ & $0.01(0.00-0.04)$ \\
\hline Lat_15 & $0.04(0.01-0.09)$ & $0.01(0.00-0.05)$ & & & $0.02(0.01-0.05)$ & $0.00(0.00-0.02)$ \\
\hline Hel_05 & $0.05(0.02-0.12)$ & $0.00(0.00-0.04)$ & $0.12(0.08-0.17)$ & $0.03(0.01-0.06)$ & $0.14(0.09-0.20)$ & $0.07(0.04-0.12)$ \\
\hline Hel_10 & $0.00(0.00-0.03)$ & $0.00(0.00-0.03)$ & & & $0.02(0.01-0.06)$ & $0.00(0.00-0.03)$ \\
\hline Hel_15 & $0.01(0.00-0.05)$ & $0.00(0.00-0.03)$ & $0.01(0.00-0.06)$ & $0.00(0.00-0.04)$ & $0.00(0.00-0.02)$ & $0.00(0.00-0.02)$ \\
\hline Cro_05 & $0.89(0.80-0.94)$ & $0.78(0.68-0.86)$ & & & $0.95(0.91-0.97)$ & $0.83(0.77-0.87)$ \\
\hline Cro_10 & $0.32(0.17-0.52)$ & $0.12(0.04-0.30)$ & $0.35(0.26-0.46)$ & $0.25(0.17-0.35)$ & $0.37(0.27-0.48)$ & $0.28(0.19-0.39)$ \\
\hline Cro_15 & $0.02(0.01-0.08)$ & $0.02(0.01-0.08)$ & $0.00(0.00-0.04)$ & $0.00(0.00-0.04)$ & $0.04(0.02-0.08)$ & $0.03(0.01-0.06)$ \\
\hline SpB_05 & $0.22(0.15-0.32)$ & $0.13(0.08-0.22)$ & $0.21(0.11-0.38)$ & $0.09(0.03-0.24)$ & $0.14(0.10-0.19)$ & $0.08(0.05-0.13)$ \\
\hline SpB_10 & $0.00(0.00-0.03)$ & $0.00(0.00-0.03)$ & & & $0.00(0.00-0.05)$ & $0.00(0.00-0.05)$ \\
\hline $\mathrm{SpB} B 15$ & & & $0.01(0.00-0.05)$ & $0.01(0.00-0.05)$ & $0.03(0.01-0.06)$ & $0.02(0.01-0.05)$ \\
\hline Fra_05 & $0.13(0.08-0.21)$ & $0.00(0.00-0.04)$ & $0.21(0.13-0.33)$ & $0.20(0.12-0.31)$ & $0.11(0.07-0.16)$ & $0.06(0.03-0.10)$ \\
\hline
\end{tabular}




\begin{tabular}{|c|c|c|c|c|c|c|}
\hline Fra_10 & & & & & $0.00(0.00-0.03)$ & $0.00(0.00-0.03)$ \\
\hline Fra_15 & & & $0.04(0.02-0.10)$ & $0.03(0.01-0.08)$ & $0.08(0.05-0.13)$ & $0.05(0.03-0.09)$ \\
\hline Cru_05 & $0.19(0.13-0.26)$ & $0.02(0.00-0.06)$ & $0.04(0.02-0.10)$ & $0.01(0.00-0.05)$ & $0.13(0.07-0.22)$ & $0.01(0.00-0.07)$ \\
\hline Cru_10 & & & $0.15(0.09-0.23)$ & $0.04(0.02-0.10)$ & $0.00(0.00-0.43)$ & $0.00(0.00-0.43)$ \\
\hline Cru_15 & $0.16(0.11-0.23)$ & $0.06(0.03-0.10)$ & $0.15(0.09-0.23)$ & $0.03(0.01-0.09)$ & & \\
\hline Sto_05 & $0.17(0.11-0.25)$ & $0.10(0.06-0.16)$ & & & $0.36(0.30-0.44)$ & $0.27(0.21-0.34)$ \\
\hline Sto_10 & & & $0.12(0.06-0.21)$ & $0.05(0.02-0.13)$ & $0.07(0.04-0.12)$ & $0.04(0.02-0.07)$ \\
\hline Sto_15 & $0.30(0.23-0.37)$ & $0.11(0.07-0.16)$ & $0.10(0.06-0.19)$ & $0.01(0.00-0.06)$ & $0.12(0.06-0.20)$ & $0.06(0.03-0.14)$ \\
\hline Abr_05 & $0.17(0.11-0.26)$ & $0.07(0.03-0.14)$ & $0.11(0.06-0.18)$ & $0.05(0.02-0.12)$ & $0.27(0.18-0.38)$ & $0.09(0.04-0.17)$ \\
\hline Abr_10 & $0.02(0.01-0.08)$ & $0.00(0.00-0.04)$ & $0.02(0.01-0.09)$ & $0.00(0.00-0.05)$ & $0.04(0.02-0.08)$ & $0.02(0.01-0.06)$ \\
\hline Abr_15 & $0.18(0.13-0.25)$ & $0.05(0.03-0.10)$ & & & $0.03(0.01-0.06)$ & $0.02(0.01-0.05)$ \\
\hline StA_05 & $0.18(0.12-0.27)$ & $0.09(0.04-0.16)$ & $0.07(0.03-0.16)$ & $0.03(0.01-0.10)$ & $0.07(0.04-0.11)$ & $0.03(0.02-0.07)$ \\
\hline StA_10 & $0.00(0.00-0.04)$ & $0.00(0.00-0.04)$ & $0.01(0.00-0.06)$ & $0.01(0.00-0.06)$ & $0.02(0.01-0.09)$ & $0.01(0.00-0.07)$ \\
\hline StA_15 & $0.03(0.01-0.08)$ & $0.01(0.00-0.05)$ & $0.02(0.01-0.07)$ & $0.01(0.00-0.06)$ & $0.00(0.00-0.05)$ & $0.00(0.00-0.05)$ \\
\hline Stb_05 & $0.05(0.02-0.10)$ & $0.02(0.01-0.07)$ & $0.06(0.03-0.12)$ & $0.02(0.01-0.07)$ & $0.04(0.01-0.10)$ & $0.04(0.01-0.1)$ \\
\hline Stb_10 & $0.03(0.01-0.09)$ & $0.01(0.00-0.06)$ & $0.02(0.01-0.07)$ & $0.02(0.01-0.07)$ & $0.02(0.01-0.05)$ & $0.01(0.00-0.04)$ \\
\hline Stb_15 & $0.04(0.02-0.08)$ & $0.02(0.01-0.06)$ & & & $0.01(0.00-0.07)$ & $0.00(0.00-0.05)$ \\
\hline
\end{tabular}


779 Table 3 Temporal model selection results for the 10 deployment groups (Group). Formula

780 indicates the final model form selected via QIC for each deployment group (Equations 1-4).

781 Response for all models was P(Broadband). ShoreDist represents the three-level factor for

782 the near (05), mid (10), and offshore (15) deployment locations. Year is the two or three

783 level factor each survey year (2013, 2014 or 2015), Delta QIC is the difference in QIC

784 scores between selected model and the next best performing model. Group AUC is the area

785 under the ROC curve for each model applied to deployment groups. Group presence (Pres.)

786 and absence (Abs.) are the proportion of presences and absences correctly identified by the

787 model for each group. Unit is the location of each C-POD within the group and each

788 individual deployment location (Dep) AUC, Pres. and Abs. are the area under the curve and

789 proportion of presences and absences correctly predicted by the model for each of the C-

790 POD locations. Dashes indicated locations were modelling was not possible due to either

791 low numbers of detections or failure to recover the C-PODs deployed at that location.

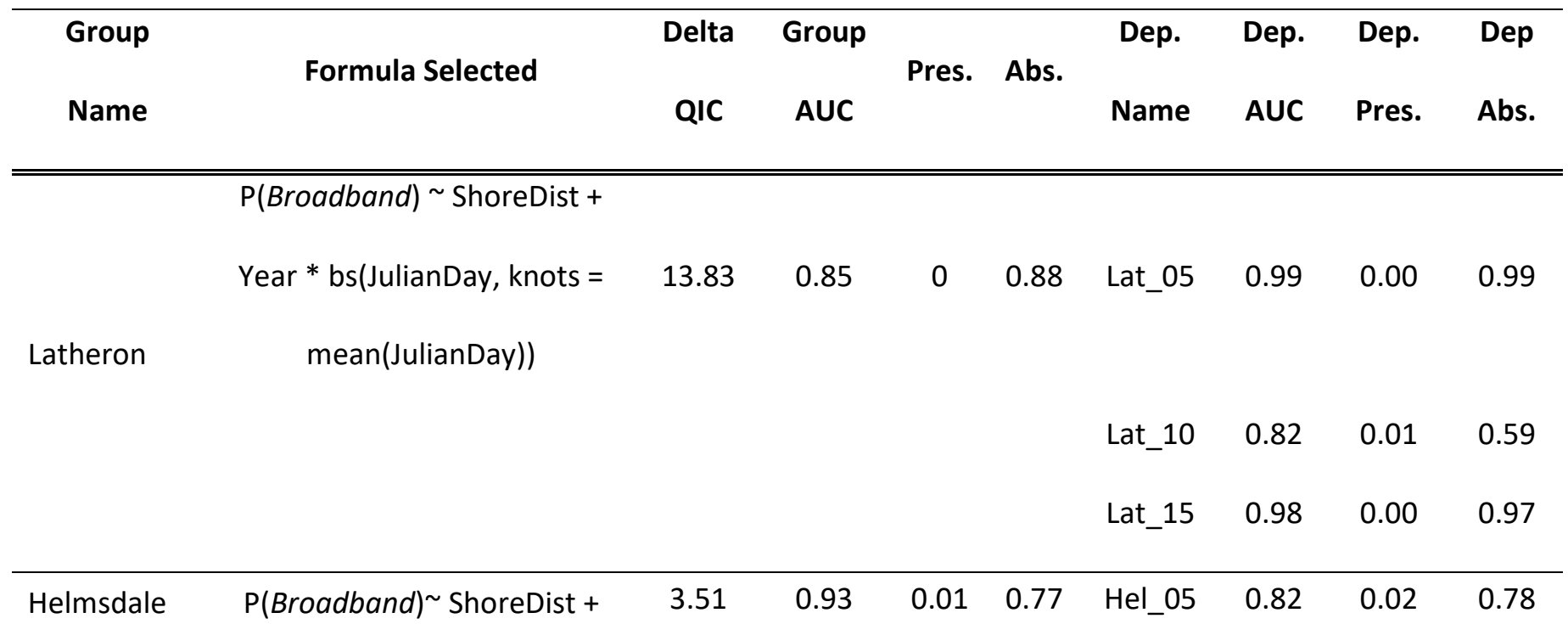




\begin{tabular}{|c|c|c|c|c|c|c|c|c|c|}
\hline \multicolumn{10}{|c|}{ Year + JulianDay } \\
\hline & & & & & & $\begin{array}{l}\text { Hel_10 } \\
\text { Hel_15 }\end{array}$ & 0.94 & 0.00 & 0.93 \\
\hline \multirow{5}{*}{ Cromarty } & $\mathrm{P}($ Broadband $) \sim$ ShoreDist + & & & & & & & & \\
\hline & Year + bs(JulianDay, knots = & 1.22 & 0.93 & 0.28 & 0.6 & Cro_05 & 0.62 & 0.53 & 0.10 \\
\hline & mean(JulianDay)) & & & & & & & & \\
\hline & & & & & & Cro_10 & 0.61 & 0.19 & 0.30 \\
\hline & & & & & & Cro_15 & 0.78 & 0.01 & 0.80 \\
\hline \multirow{5}{*}{ Spey Bay } & $\mathrm{P}($ Broadband $) \sim$ Year + & & & & & & & & \\
\hline & ShoreDist * bs(JulianDay, & 5.34 & 0.81 & 0.04 & 0.63 & SpB_05 & 0.63 & 0.05 & 0.63 \\
\hline & knots $=$ mean(JulianDay $))$ & & & & & & & & \\
\hline & & & & & & SpB_10 & & & \\
\hline & & & & & & SpB_15 & 0.75 & 0.01 & 0.55 \\
\hline \multirow{4}{*}{ Fraserburgh } & $\mathrm{P}($ Broadband $) \sim$ ShoreDist + & & & & & & & & \\
\hline & & 2.52 & 0.75 & 0.04 & 0.48 & Fra_05 & 0.70 & 0.03 & 0.81 \\
\hline & & & & & & Fra_10 & 0.99 & 0.00 & 0.98 \\
\hline & & & & & & Fra_15 & 0.54 & 0.04 & 0.40 \\
\hline \multirow{4}{*}{ Cruden Bay } & $\mathrm{P}($ Broadband $) \sim$ ShoreDist + & & & & & & & & \\
\hline & Yor + & 1.85 & 0.63 & 0.03 & 0.33 & Cru_05 & 0.64 & 0.01 & 0.72 \\
\hline & & & & & & Cru_10 & 0.22 & 0.03 & 0.13 \\
\hline & & & & & & Cru_15 & 0.61 & 0.02 & 0.82 \\
\hline \multirow[b]{2}{*}{ Stonehaven } & $\mathrm{P}($ Broadband $) \sim$ Year + & & & & & & & & \\
\hline & ShoreDist * bs(JulianDay, & 5.73 & 0.79 & 0.06 & 0.77 & Sto_05 & 0.71 & 0.13 & 0.63 \\
\hline
\end{tabular}


knots = mean(JulianDay))

Sto_10 $0.63 \quad 0.02 \quad 0.67$

Sto_15 $0.81 \quad 0.05 \quad 0.82$

\section{$\mathrm{P}($ Broadband $) \sim$ Year +}

$\begin{array}{lllllllll}\text { ShoreDist * bs(JulianDay, } & 1.39 & 0.82 & 0.03 & 0.51 & \text { Abr_05 } & 0.61 & 0.04 & 0.58\end{array}$

Arborath $\quad$ knots $=$ mean $(J u l i a n D a y))$

$\begin{array}{llll}\text { Abr_10 } & 0.98 & 0.01 & 0.96\end{array}$

$\begin{array}{llll}\text { Abr_15 } & 0.76 & 0.03 & 0.49\end{array}$

$\mathrm{P}($ Broadband $) \sim$ ShoreDist +

$\begin{array}{lllllllll}\text { Year } * \text { bs(JulianDay, knots }= & 8.46 & 0.85 & 0.02 & 0.82 & \text { StA_05 } & 0.83 & 0.04 & 0.72\end{array}$

St Andrews mean(JulianDay))

StA_10 $0.81 \quad 0.00 \quad 0.72$

StA_15 $0.63 \quad 0.00 \quad 0.51$

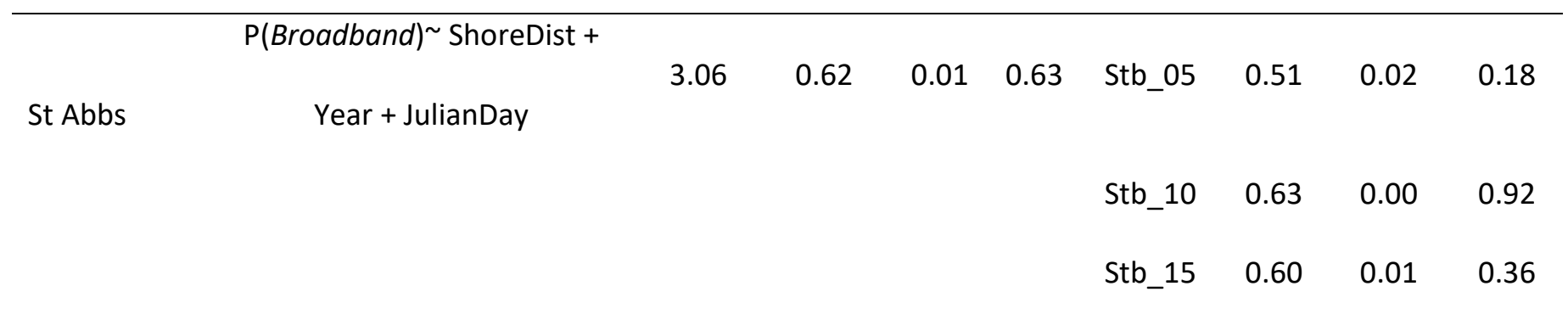

793 
794 Table 4 GAMM summary for the parametric and smooth coefficient estimates, standard errors, estimated degrees of 795 freedom (EDF), reference degrees of freedom (Ref.df), F, $t$ and $p$-values for the final habitat model. Smooth factors

796 (Distance to nearest Point Of Aggregation and Distance to Shore) are added as a main effect.

\section{Model Formula}

$\mathrm{P}($ Broadband $) \sim \mathrm{s}($ DistToPOA, bs = "ts", $\mathrm{k}=3)+\mathrm{s}($ Depth, $\mathrm{bs}=$ "ts" $)+\mathrm{s}($ DistToShore, $\mathrm{bs}=$ "ts" $)+$ POIName + Season+ DistToPOA+ DistToShore

\begin{tabular}{|c|c|c|c|c|}
\hline \multicolumn{5}{|c|}{ Parametric coefficients } \\
\hline & Estimate & Std. Error & t value & $\operatorname{Pr}(>|t|)$ \\
\hline (Intercept) & -2.70586 & 0.17708 & -15.281 & $<.001$ \\
\hline Dee & -0.63122 & 0.34879 & -1.81 & 0.070 \\
\hline Esk & -1.02055 & 0.31654 & -3.224 & 0.001 \\
\hline Spey & -1.24386 & 0.27673 & -4.495 & $<.001$ \\
\hline Tay Firth & -0.64207 & 0.35049 & -1.832 & 0.067 \\
\hline Tweed & -2.41157 & 0.44156 & -5.461 & $<.001$ \\
\hline SeasonSpring & -0.06665 & 0.16495 & -0.404 & 0.686 \\
\hline SeasonSummer & 0.03319 & 0.12101 & 0.274 & 0.784 \\
\hline \multicolumn{5}{|c|}{ Approximate significance of smooth terms } \\
\hline & EDF & Ref.df & $\mathrm{F}$ & $\mathrm{p}$-value \\
\hline s(DistToPOA) & 1.917 & 2 & 55.264 & $<.001$ \\
\hline s(Depth_m) & 4.686 & 9 & 6.233 & $<.001$ \\
\hline s(DistToShore) & 4.961 & 9 & 9.094 & $<.001$ \\
\hline R-sq.(adj) $=0.322, \quad$ Scale est. $=1, n=9181$ & & & & \\
\hline
\end{tabular}




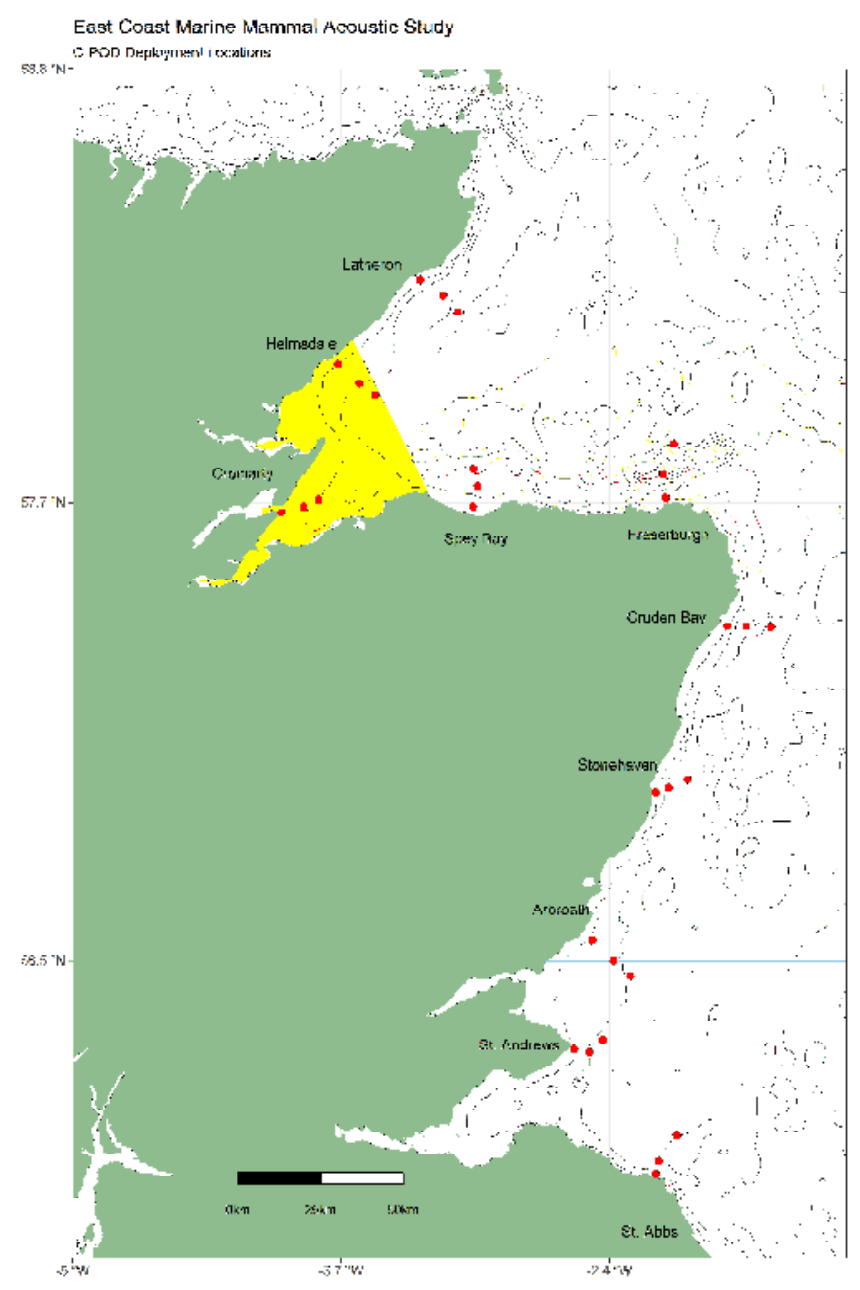

801 Figure 1. Study area including the Moray Firth Special Area of Conservation (yellow) and

802 deployment locations of the East Coast Marine Mammal Acoustic Study (red points) and 803 associated deployment group names.

804 


\section{Daily Occupancy Rates 2013}
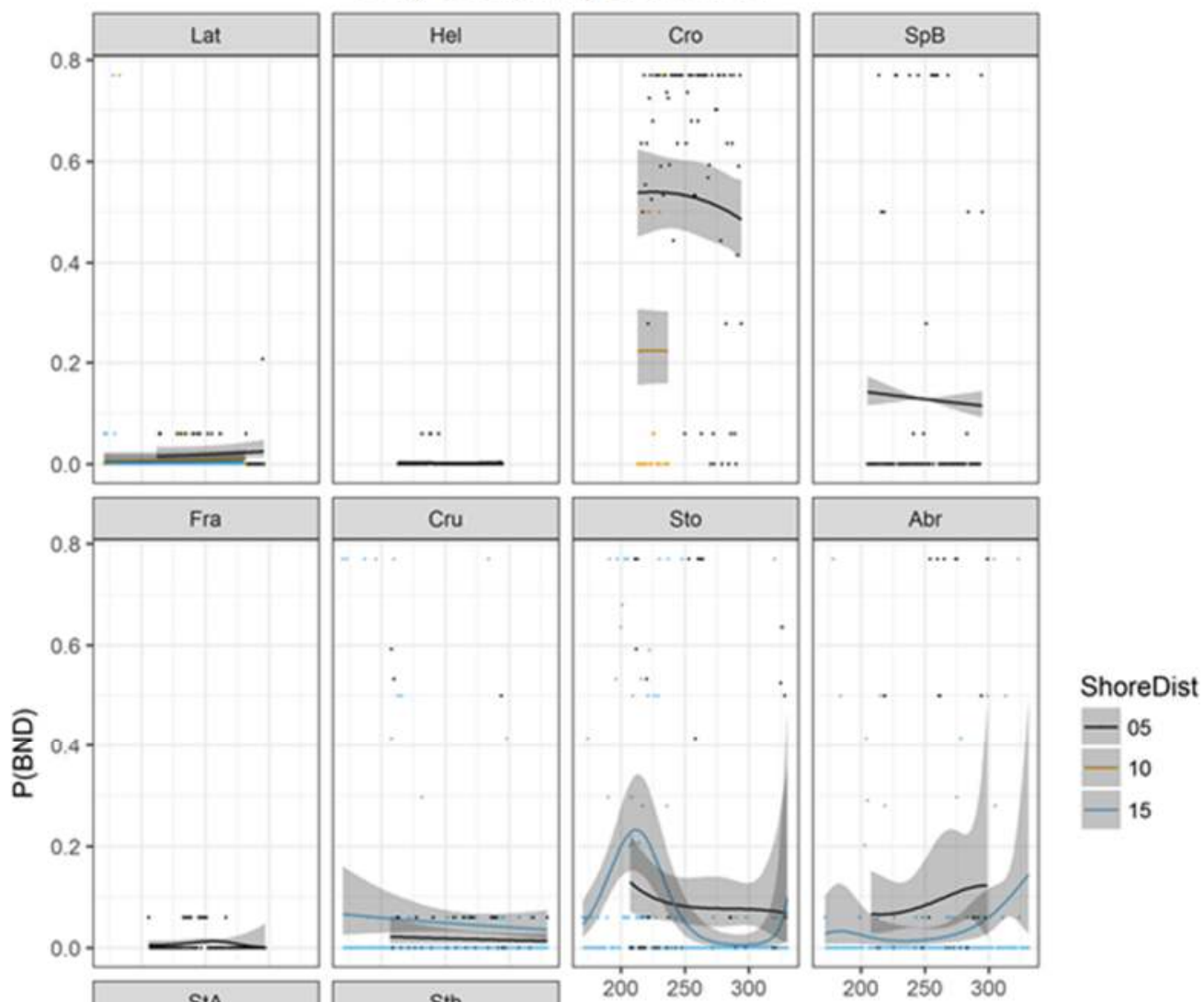

805
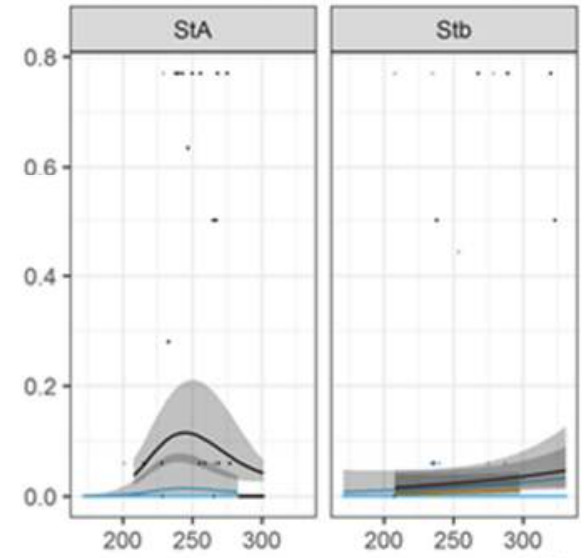

Julian Day

Figure 2. Observed (points) and 95\% confidence interval of the modelled occupancy (shaded) for

807 the 2013 near (05) mid (10) and offshore (15) deployment sites (panels). Colour indicates

808 distance from shore as a factor. 


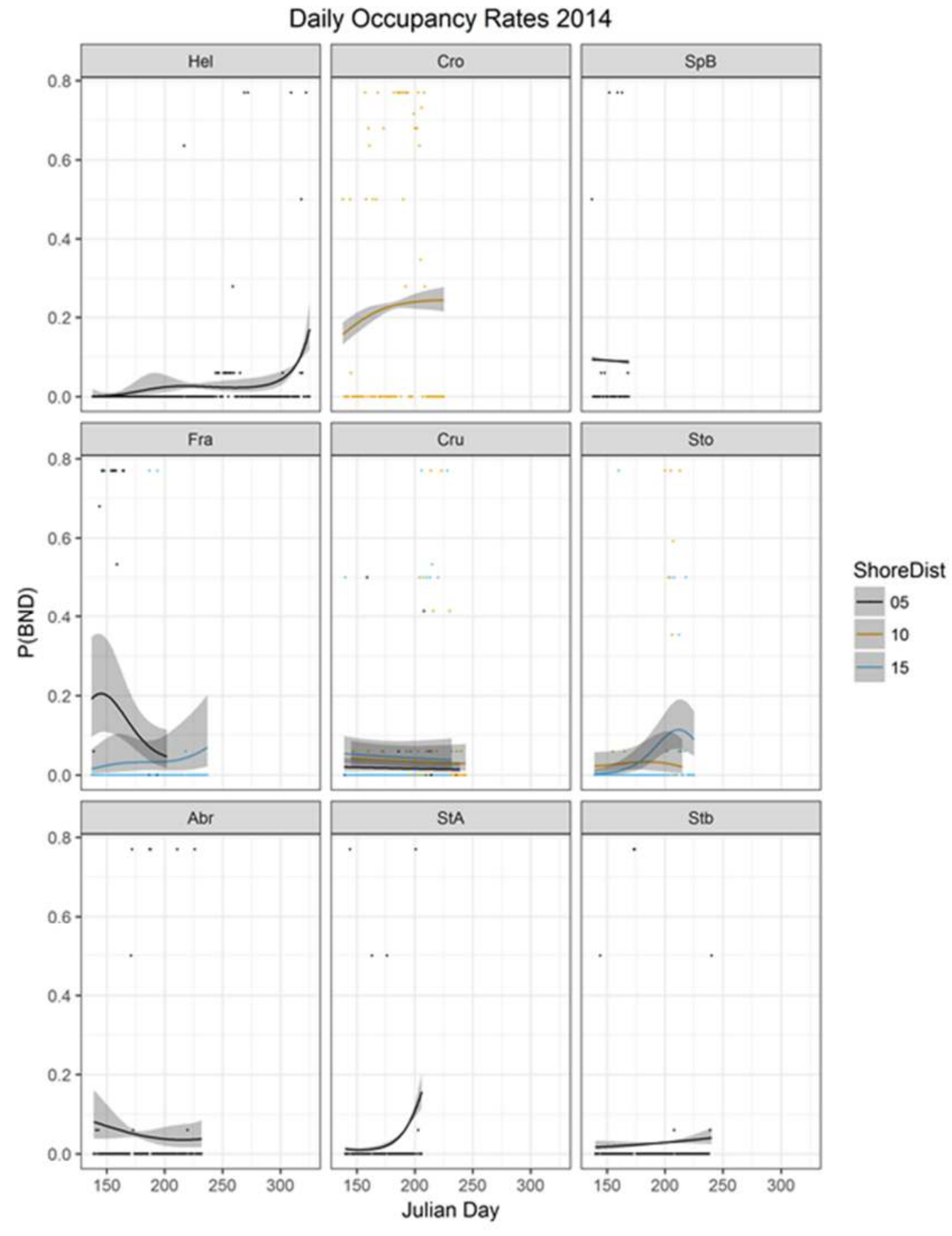

811 Figure 3. Observed (points) and 95\% confidence interval of the modelled occupancy (shaded) for

812 the 2014 near (05) mid (10) and offshore (15) deployment sites (panels). Colour indicates

813 distance from shore as a factor. 
Daily Occupancy Rates 2015
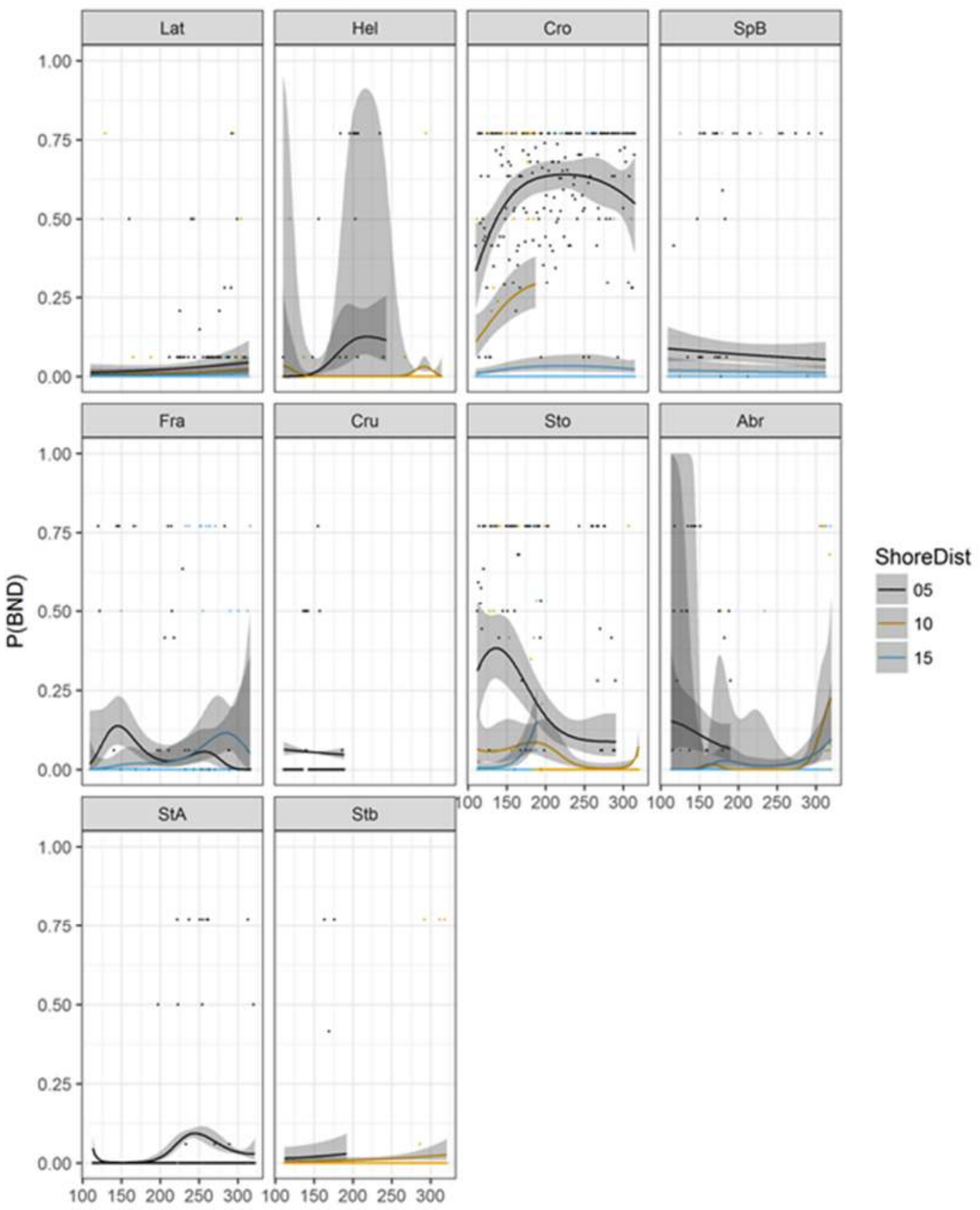

Julian Day

816 Figure 4. Observed (points) and 95\% confidence interval of the modelled occupancy (shaded) for

817 the 2015 near (05) mid (10) and offshore (15) deployment sites (panels). Colour indicates

818 distance from shore as a factor. 

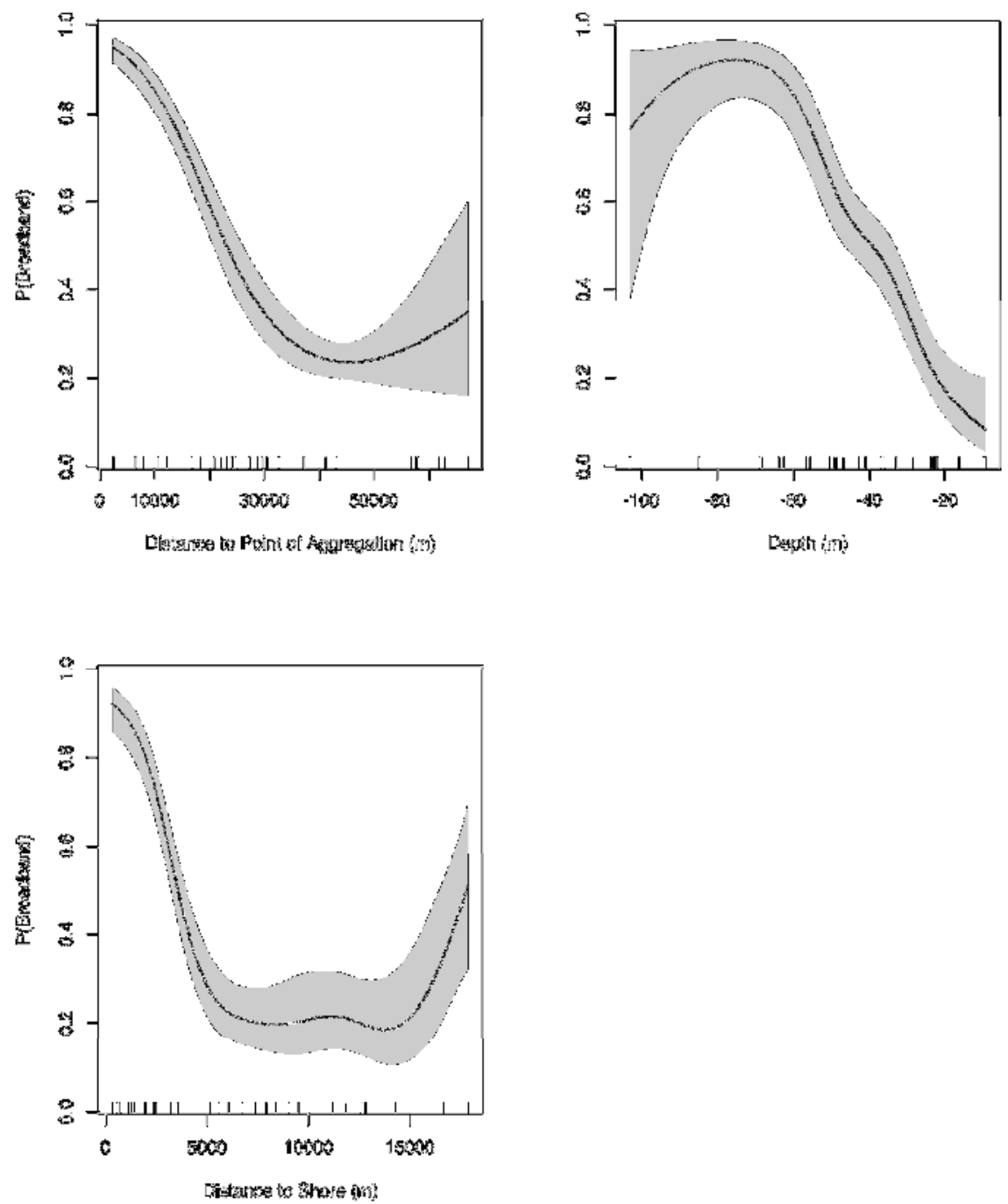

821 Figure 5. Two dimensional representations of the binomial smooths for the habitat GAMM.

822 Shaded area represents the probability of detecting a broadband echolocation click train on a

823 given C-POD as a function of the CPOD's distance to the nearest point of aggregation (top left),

824 deployment depth (top right) and distance to shore (bottom). Shaded areas represent 95\%

825 confidence intervals and dashes on $\mathrm{X}$-axis are rug plot of deployment variables. 


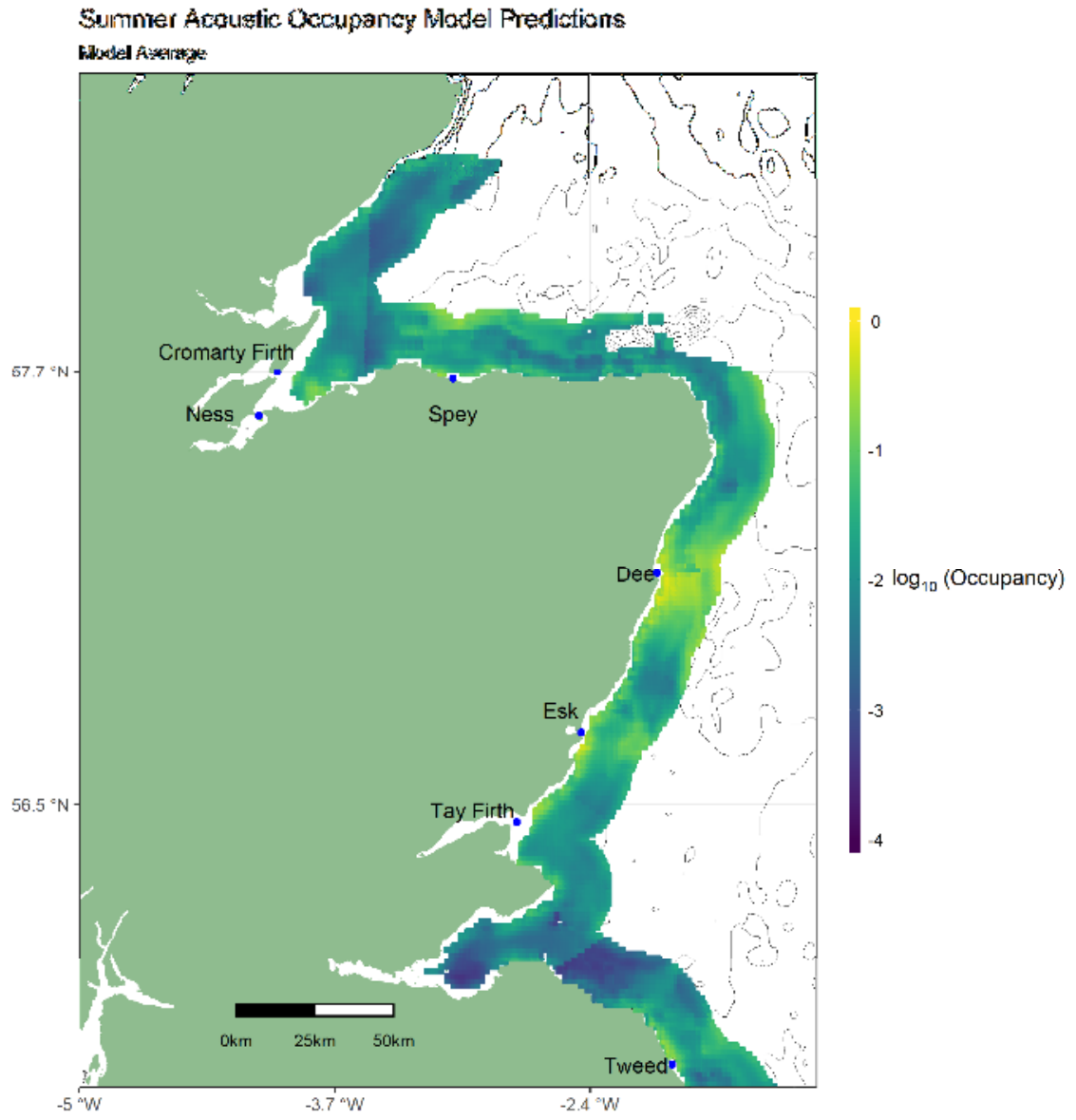

827

828 Figure 6. Predicted broadband occupancy throughout the east coast habitat. Predictions based on

829 GAMM analysis of CPOD acoustic records from 2013-2015. Data are standardized to year 2015 
830 and season is set to summer 


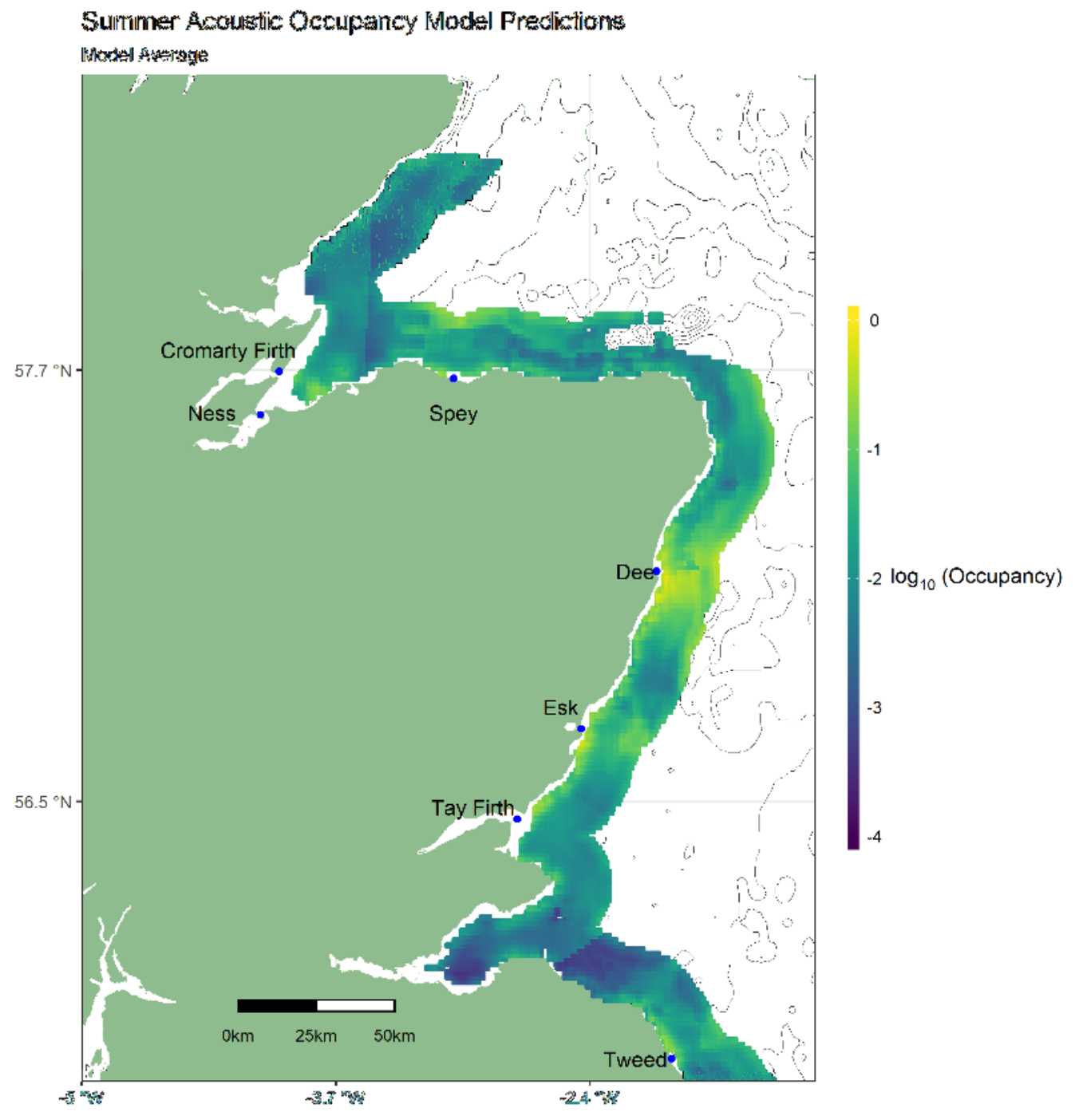

